\title{
Review of the USA National Phenology Network
}

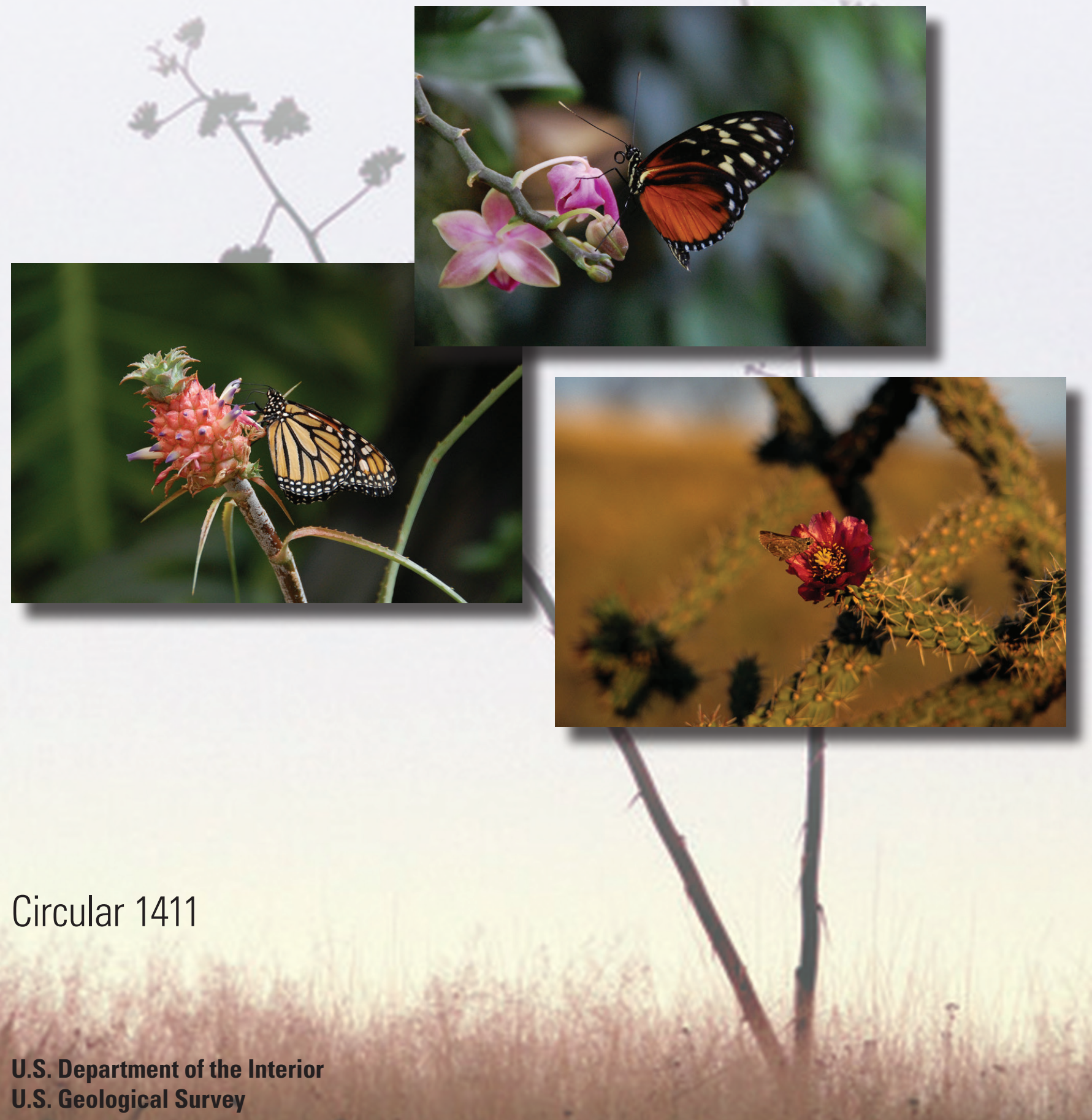




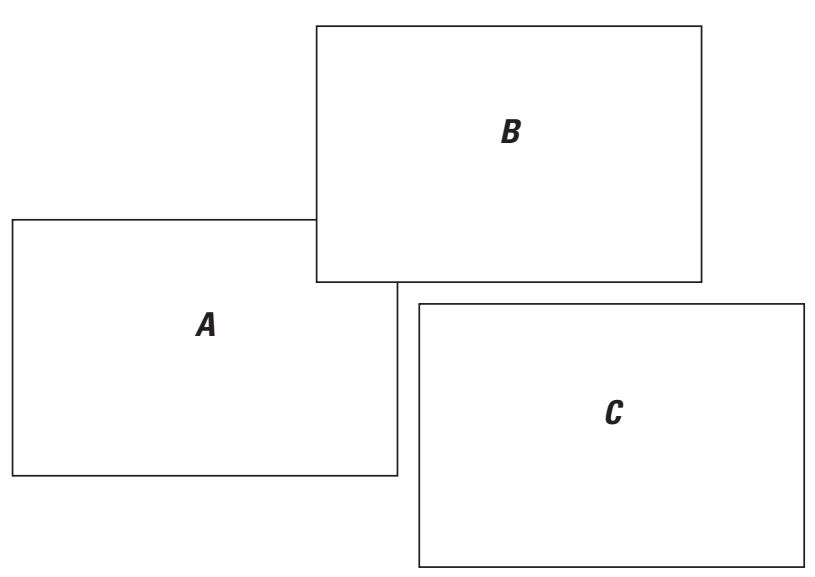

\section{Front cover photographs.}

$\boldsymbol{A}$, Plants and animals often lead symbiotic lives: plants provide nectar, pollen, habitat, or other resources to animals, and animals provide services to plants such as pollination or seed dispersal. The USA-NPN focuses on understanding spatial and temporal overlap between interacting species. Photograph by Brian F. Powell.

$\boldsymbol{B}$, Seed production by plants such as this agave within a matrix of perennial native and invasive grasses is a critical life-history stage for reproduction. The USA-NPN enables the tracking of plant and animal reproductive —or phenological—events on a national scale. Photograph by Brian F. Powell.

C, Nature's Notebook, a project of the USA-NPN, is a multitaxa plant and animal observing system that enables monitoring and analysis of interacting species, such as this insect visitor to a cholla cactus. Photograph by Brian F. Powell.

Background, Modified image of seed production by plants. Photograph by Brian F. Powell. 


\section{Review of the USA National Phenology Network}

Edited by Pierre D. Glynn and Timothy W. Owen, with contributions and recommendations by the 2014 USA National Phenology Network (USA-NPN)

Review Panel and appendixes by Geoffrey M. Henebry and Jake F. Weltzin

\section{USA-NPN Review Panel Members:}

Pierre Glynn (Chair), U.S. Geological Survey

Bradley Reed (Vice-Chair), U.S. Geological Survey

Robert Cook, Oak Ridge National Laboratory

Frank Davis, University of California in Santa Barbara

David Medvigy, Princeton University

Russell Monson, University of Arizona

David Schimel, Jet Propulsion Laboratory

Mark Shaffer, U.S. Fish and Wildlife Service

Timothy Owen (Secretary), National Oceanic and Atmospheric Administration

Circular 1411

\section{U.S. Department of the Interior \\ U.S. Geological Survey}




\title{
U.S. Department of the Interior SALLY JEWELL, Secretary
}

\section{U.S. Geological Survey \\ Suzette M. Kimball, Acting Director}

\author{
U.S. Geological Survey, Reston, Virginia: 2015
}

For more information on the USGS - the Federal source for science about the Earth, its natural and living resources, natural hazards, and the environment—visit http://www.usgs.gov or call 1-888-ASK-USGS.

For an overview of USGS information products, including maps, imagery, and publications, visit http://www.usgs.gov/pubprod/.

Any use of trade, firm, or product names is for descriptive purposes only and does not imply endorsement by the U.S. Government.

Although this information product, for the most part, is in the public domain, it also may contain copyrighted materials as noted in the text. Permission to reproduce copyrighted items must be secured from the copyright owner.

Suggested citation:

Glynn, P.D., and Owen, T.W., eds., 2015, Review of the USA National Phenology Network: U.S. Geological Survey Circular 1411, 27 p., http://dx.doi.org/10.3133/cir1411.

ISSN 2330-5703 (online) 


\section{Contents}

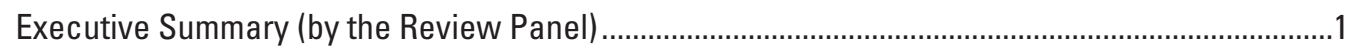

Phenology: Introduction and Importance to Federal Agencies ....................................................

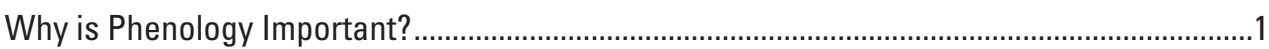

Why Is Phenology Relevant to the Mission of the U.S. Geological Survey and the

Department of the Interior? .....................................................................................

Why Is Phenology Relevant to Other Federal Institutions? ......................................................

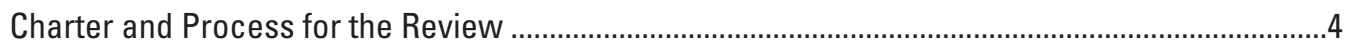

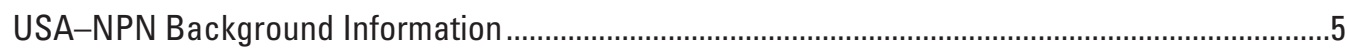

A Short History of the USA-NPN .........................................................................................

Role of the Advisory Committee .......................................................................................

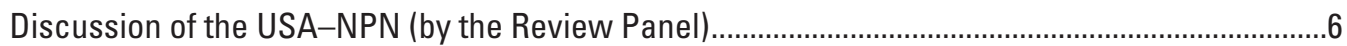

Panel's Perspective on Accomplishments of the USA-NPN from 2007 to 2014........................6

Panel's Perspective on Risks and Needs of the USA-NPN Going Forward .............................6

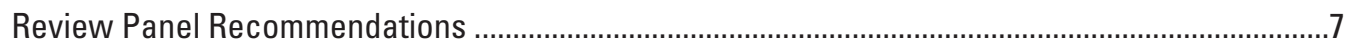

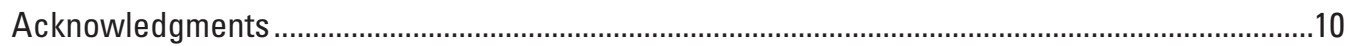

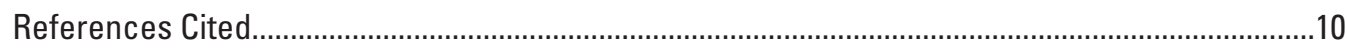

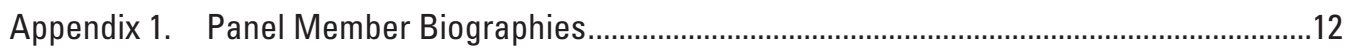

Appendix 2. Agenda and Attendees of the April 2014 Review Workshop .....................................14

Appendix 3. List of Documents Provided to the Review Panel...................................................18

Appendix 4. National Coordinating Office Perspective of USA-NPN Accomplishments

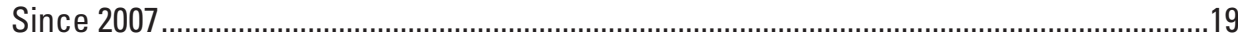

Status of Key USA-NPN Partnerships (Numbers Updated to May 2015) ...............................19

Metrics Of USA-NPN Accomplishments and Outcomes ......................................................20

Key Accomplishments Since 2007 Include (Numbers Updated to May 2015)................20

Key Outcomes Since 2007 Include (Numbers as of May 2015) ........................................20

Publications that Rely on Contemporary Data from the National Phenology Database .......20

Publications that Rely on Legacy Data from the National Phenology Database .....................21

Appendix 5. Advisory Committee Contributions and Perspective of USA-NPN

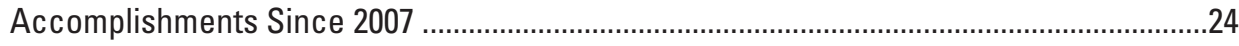

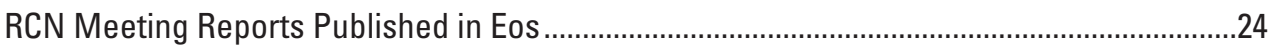

Examples of Synthesis Articles that Originated at RCN Meetings ...........................................25

Examples of Publications from NCEAS Working Group on Forecasting Phenology ...............26

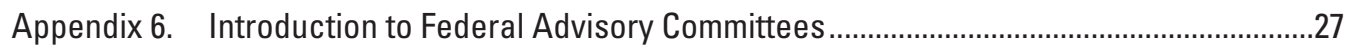

\section{Figures}

4-1. Annual accumulation of records submitted via Nature's Notebook to the USA-NPN National Phenology Database from January 2009 through May 2015...........22

4-2. Spatial distribution of records by registered Nature's Notebook site submitted to the USA-NPN National Phenology Database in 2009 and between 2009 and May 2015 



\title{
Review of the USA National Phenology Network
}

\author{
Edited by Pierre D. Glynn ${ }^{1}$ and Timothy W. Owen²
}

\section{Executive Summary (by the Review Panel $)^{3}$}

In January 2014, leadership from the U.S. Geological Survey (USGS) Ecosystems Mission Area commissioned a review of the USA National Phenology Network (USA-NPN) Program. The Ecosystems Mission Area has a key stake in the USA-NPN, providing both supervision of its Director and most of the appropriated funds. The products and objectives of the program are relevant to six of the seven USGS Mission Areas as well as to at least four Department of the Interior (DOI) bureaus.

A nine-person panel of reviewers, with representatives from the USGS, other Federal agencies, and academia, was convened to provide advice and recommendations to USGS leadership. Specifically, the panel was asked to assess the science utility of having a National Phenology Network; to consider USGS science mission and DOI management needs served by the USA-NPN; and to consider the utility of the USA-NPN to other Federal agency science missions or management needs (including the National Science Foundation $[\mathrm{NSF}]$ and university research funded by the NSF and other government agencies).

This report summarizes the panel's findings and offers five recommendations for USGS leadership:

1. Commit to stable USA-NPN funding and increase accountability.

2. Establish a Federal Steering Committee, led by the USGS, and a separate Scientific Phenology User Group.

3. Emphasize continental-scale phenology data and information.

\footnotetext{
${ }^{1}$ U.S. Geological Survey.
}

${ }^{2}$ National Oceanic and Atmospheric Administration.

${ }^{3}$ Review panel (and its authorship in this document) refers to the 2014 USA-NPN review panel, which included the following members: Robert Cook, Frank Davis, Pierre Glynn (Chair), David Medvigy, Russell Monson, Bradley Reed (Vice-Chair), David Schimel, and Mark Shaffer. Timothy Owen served as Panel Secretary. Panel member biographies are provided in appendix 1.
4. Formalize volunteer engagement in phenology data collection.

5. Integrate phenology information into USGS science.

The panel generally affirms the value of the USA-NPN program and finds that the program is successfully meeting the needs of its stakeholders, including the USGS. However, the USGS needs to be more engaged in the program, providing leadership and setting priorities for the future. The USA-NPN, in turn, needs to deliver more clearly defined, DOI-relevant, USGS-integrated, data product lines that have the broadest possible spatial and temporal scope to meet user needs across the United States.

The panel recommends that the USA-NPN National Coordinating Office (NCO) establish an implementation plan that addresses all of the panel recommendations, with priorities, timelines, and assumptions to move the program forward successfully.

\section{Phenology: Introduction and Importance to Federal Agencies}

\begin{abstract}
Many of the events of the annual cycle recur year after year in a regular order. A year-to-year record of this order is a record of the rates at which solar energy flows to and through living things. They are the arteries of the land. By tracing their response to the sun, phenology may eventually shed some light on that ultimate enigma, the land's inner workings.
\end{abstract}

—Leopold and Jones (1947)

\section{Why is Phenology Important?}

Phenology is an integrative science. Phenology is the science of the "appearance of changes" in the seasonal cycle and (or) in the life cycle of organisms - both plants and animals. In addition to changes in the state of specific organisms and their appearance, behavior, and (or) migration, phenology also includes the timing of reproduction and the timing of interactions between and among species, such as those involving predator-prey interactions, pollination, seed dispersal, and 
the emergence of insect or fungal symbionts and parasites. Phenology depends on the interactions resulting from (1) an organism's genetic composition, (2) the translation of that composition into behavioral, physiological, or morphological phenotypes (or appearances), and (3) the changing environment, which the organism experiences and to which it possibly adapts. Thus, phenology reflects the underlying interactions and an integration of numerous biotic and abiotic processes that connect an organism to its environment. Phenology is a useful diagnostic tool for discerning the impact of environmental changes on all organisms; its use is analogous to determining a human pulse, heart rate, or blood pressure to assess environmental impacts on human health.

Phenology has been of interest and use to humans for thousands of years: hunting, fishing, animal husbandry, the growing of crops, and the avoidance of disease were all helped by phenological observations, as was the planning and timing of cultural rituals. Written records of phenological observations were made as early as 1736 by people such as Robert Marsham in England and Carl Linnaeus (1707-78) in Sweden. René-Antoine Ferchault de Réaumur studied the relation between environmental temperatures and the timing of flowering in 1735. More recently, Aldo Leopold understood phenology to be critical to understanding "the land's inner workings." He maintained detailed records of the arrival of certain bird migrants, the flowering of plants, and the emergence of certain animals from hibernation. When these types of "appearance" records are compiled with parallel measurements of climate, human disturbance, or changes in the behavior of species and their interdependencies, scientists can begin to understand how our changing world is affecting organisms. This level of analysis goes beyond climate monitoring or analysis of changes in the Earth's atmosphere - it brings organisms and natural ecological relations into the discussion. It provides us with a sharper sense of the impact of environmental change, rather than simply the amount of environmental change. Phenology is an integrative science and it is truly an ecological science. Phenology, importantly, provides "canary in the coal mine" indicators of change. We rely on these phenological indicators to determine the effects of climate change (and to a lesser extent land-use change) on the Earth's natural and agricultural biota.

\section{Why Is Phenology Relevant to the Mission of the U.S. Geological Survey and the Department of the Interior?}

Because phenology investigates the timing of biological events, the data and knowledge produced by the USA-NPN are important to the USGS Ecosystems Mission Area and its stated objectives of conducting research and monitoring on freshwater, terrestrial, and marine ecosystems and the fish and wildlife within them. Although the Ecosystems Mission Area currently supervises the Director of the USA-NPN and provides most of the appropriated funds for the program, the products and objectives of the USA-NPN are relevant to six of the seven USGS Mission Areas, as well as to at least four DOI agencies.

Within the USGS, the USA-NPN is also highly relevant to the Climate and Land Use Change Mission Area. Indeed, the National Climate Change and Wildlife Science Center (NCCWSC) has provided significant funding over the last several years to the USA-NPN. Phenology influences the population dynamics of many fish and wildlife species, and changes in temperature and precipitation resulting from climate change are having demonstrable impacts on plant and animal populations. The NCCWSC recognizes that phenology research can inform climate change adaptation planning by the resource management community. Specifically, the NCCWSC seeks greater understanding of the biological community responses of forest, grassland, wetland, riparian, and other environments to phenological changes, including

- The timing of vegetative green-up and consequent impacts on migratory species that depend on certain vegetative characteristics for optimal breeding/calving, foraging, or critical habitats used during migration;

- The impacts of drought on the timing of seasonal vegetative changes; and

- The evidence of predator-prey mismatch caused by different seasonal cues within the relation.

According to its leadership, the NCCWSC welcomes future collaboration with the USA-NPN through sponsored research to address NCCWSC program objectives. In addition, the NCCWSC seeks USA-NPN technical expertise when conducting reviews of research proposals relating to phenology.

The Climate and Land Use Change Mission Area also has other programs with direct ties to phenology, including the Land Change Science program which has sponsored research on the causes and consequences of land change across the Nation and the impact on phenology. The Land Remote Sensing program produces an operational remote sensing (MODISbased) phenology product and operates the Landsat satellite series which have high potential for advancing our knowledge of phenology across large areas by producing images at a 30-meter resolution.

Other USGS Mission Areas that should also have interest in the USA-NPN include (1) the Water Mission Area, (2) the Natural Hazards Mission Area, (3) the Environmental Health Mission Area, and (4) the Core Science Systems Mission Area. Phenology can inform water availability and water-quality studies in the Water Mission Area. For example, the leaf-out of trees and other plants, or their new growth in springtime, directly affects both runoff and water uptake by plants, the primary component of evapotranspiration (ET). The severe biotic effects of drought, or of a lack of water availability, are seen most importantly in the health of plants, which also affects the timing of their growth or senescence. The timing (and seasonal extent) of plant growth and senescence affects water quality through plant uptake/release of important nutrients, such as 
nitrogen and phosphorus. These nutrients, often in excess as a result of agricultural practices, are a common cause of environmental degradation.

The Natural Hazards Mission Area has an interest in the USA-NPN because advances or delays in both snowmelt and leafout can affect the timing and extent of plant water stress, fuel moisture conditions, and potentially the timing, duration, and severity of the forest fire season. For example, following wet winters, extensive "blooms" of non-native, winter annual grasses (e.g., cheatgrass and red brome) and subsequent drying can fuel extensive and fast-moving wildfires in the deserts of the American West. Phenology at the time of the burn (natural and prescribed) also has myriad effects on post-fire recovery of vegetation and wildlife across different biomes (e.g., forests, shrublands, and grasslands). From a perspective beyond hazards, phenology also should be of great interest to the Ecosystems Mission Area. Similarly, phenology is of potential interest to the Environmental Health Mission Area because it can document and (or) impact environmental health not only through its connection to the cycling of nutrients (or other biotically mediated contaminants) but also through its connection to the appearance/disappearance or prevalence of pests, parasites, microbial infections, and zoonotic diseases. Lastly, the USGS Core Science Systems Mission Area has a potential interest in the USA-NPN because of its responsibilities in managing the data and information archives of the USGS and in making them available to external stakeholders, the greater scientific community, and the public.

Phenology is important to USGS Mission Areas, but USGS science is also broadly important to phenology. Indeed, USGS science provides observations and understanding of the hydrological, geological, and biophysical features of landscapes and ecological habitats; and these features can alter the phenological responses to climate and land-use change.

Phenology is important to USGS science because it provides greater understanding of natural resources and environments and their potential disruptions in the face of climate change and land-use change. Similar reasons make phenology and the USA-NPN important to the land-management and resource management agencies of the DOI, including the U.S. Fish and Wildlife Service (USFWS), the Bureau of Land Management (BLM), the Bureau of Ocean Energy Management (BOEM), and the National Park Service (NPS). From knowing when to prepare the National Mall for the influx of spring visitors to view Washington, D.C.'s famous cherry blossoms, to knowing when to open the fall hunting season for migratory waterfowl, or the best time to conduct controlled burns, managers and many private entities need good information on the timing of important natural events. Such information allows agencies, businesses, and individuals to plan their activities efficiently and to avoid making commitments that, should things not play out as anticipated, could prove to be costly. Phenological data and understanding are also potentially important for the protection and management of the "trust species" of the DOI, such as species on the "threatened and endangered" list. This statement comes with the understanding that (1) it is difficult to obtain good phenological records for rare or disappearing species, and (2) there are many additional factors to consider, beyond phenology, in species conservation and management.

\section{Why Is Phenology Relevant to Other Federal Institutions?}

The National Oceanic and Atmospheric Administration (NOAA) National Weather Service has maintained a volunteer weather observation program, called the Cooperative Observer Program, for over a century. The network, which includes more than 7,000 stations reporting daily measurements of temperature, precipitation, and snow, is a primary source of data for meteorological, climatological, and hydrological applications. The tightly coupled relation between climate and phenology is evidenced in many studies, such as the documented advance in spring onset and shifts in plant hardiness zones in recent decades. The ability to accurately assess and monitor the ecological impacts of climate variability and change relies partly on standardized, sustained, and synoptic phenological observations at scales comparable to those at which we monitor and understand weather and climate. The USA-NPN has been an important source for phenological information that meets this requirement. Continued and strengthened commitment to national-scale phenological information is critical to sustained national assessments of the impacts of climate change.

The U.S. Department of Agriculture (USDA) closely monitors crop phenology (1) for projections of crop production and (2) to document the progress and potential vulnerabilities of a range of crops to drought, insects, and other disturbances. The USDA Agricultural Research Service (ARS) and the USDA National Institute of Food and Agriculture (NIFA) are working with the USA-NPN through the ARS Long-Term Agroecosystem Research (LTAR) network and the NIFA cooperative extensions to further develop and coordinate phenological monitoring. Additionally, within the USDA, the U.S. Forest Service's (USFS) Strategic Framework for Responding to Climate Change (2008) and the subsequent National Roadmap for Responding to Climate Change (2011) provide a set of principles for meeting the challenges of managing the national forest system in an era of climate variation and change. To demonstrate that measures are being taken to mitigate and adapt to these changes, individual units in the system are required, on an annual basis, to answer the question, "Is monitoring being conducted to track changing conditions of species and watersheds, forest and grassland health and other measures, and the effectiveness of treatment programs?" The U.S. Forest Service is partnering with the USA-NPN to help units respond to this question and help meet their requirements related to climate change and broad-scale monitoring. In addition to fulfilling these annual requirements, phenology monitoring can help units understand fundamental questions about how organisms are responding to changes in climate and can help inform management decisions. 
Phenology also has implications for human health and, consequently, for agencies such as the Centers for Disease Control and Prevention (CDC), the National Institute of Allergy and Infectious Diseases (NIAID), and possibly the National Institute of Environmental Health Sciences (NIEHS). Predicting the timing and production of allergy-causing pollen from a number of species could greatly improve preventative treatments. In addition, outbreaks of vector-borne diseases such as hantavirus (rodents), Lyme disease (ticks), and West Nile virus (mosquito) are related to the spatial and temporal aspects of the habitat of the vector, including its phenological dimensions. Understanding, monitoring, and predicting the conditions that can potentially lead to a population increase of the disease vector can greatly enhance preparations for treating a disease outbreak or even preventing it.

The Famine Early Warning Systems Network (FEWS NET) is an effort begun by the U.S. Agency for International Development (USAID) in the 1980s. It involves several Federal agencies (USGS, NOAA, National Aeronautics and Space Administration [NASA], USDA) as well as the Food and Agriculture Organization of the United Nations. Crop phenology and other inputs are used by FEWS NET to calculate potential evapotranspiration and crop water requirements as well as to provide early warning and identification of areas susceptible to food insecurity. The network operates in many parts of Africa, Central America and the Caribbean, and Central Asia.

As part of its Earth observing mission, NASA uses spacebased remote sensing capabilities (including USGS-operated Landsat satellites) to monitor phenology in coordination with ground-based observations such as those provided by the USA-NPN. This coordination enables NASA to provide information, at regional to global scales, on the phenological response of vegetation (and agricultural products) to climate and land-use changes from season to season and year to year. The capabilities and resources of NASA complement and support work conducted by other agencies and by university researchers. For example, NASA supports the Vegetation Index and Phenology (VIP) laboratory at the University of Arizona and provides land phenology monitoring of several National Parks through the NPS Inventory and Monitoring (I\&M) program.

Phenological monitoring is also of interest to the National Science Foundation (NSF) and to many of the scientists, programs, observatories, and networks that receive funding from NSF, such as the National Ecological Observatory Network (NEON), the Long-Term Ecological Research (LTER) network, and biological field stations. Indeed, funding provided by NSF was critical in initiating the USA-NPN, as will be discussed later in this report.

Beyond government agencies and academia, phenological observations and understanding are also of interest to a number of nongovernmental organizations and community efforts, especially those with a biological conservation and (or) observation mission (for example, NatureServe, National Wildlife Federation, eBird). There are many other potential users (and providers) of phenology information including (1) regional coordination efforts such as the DOI's Landscape Conservation Cooperatives (LCC's; http://ccnetwork. org/) and Climate Science Centers (CSC's; http://doi.gov/csc/ index.cfm), (2) national initiatives and programs such as the National Climate Assessment (http://www.globalchange.gov/ ncadac), and (3) international efforts such as the Intergovernmental Platform on Biodiversity and Ecosystem Services (http://www.ipbes.net/).

Phenological observations and understanding transcend the needs and capabilities of any one institution, primarily because of the diversity of measurements that are needed and because of the need to integrate across spatial and temporal scales. Indeed, properly scaling observations from the individual measurements of human observers to those made by satellites is critical in assessing phenology conditions across large areas of the landscape (such as done by NASA, USGS, and FEWS NET). Much of the remote sensing phenology work to date has involved the use of frequent (near daily) satellite observations from the Moderate Resolution Imaging Spectroradiometer (MODIS) with spatial scales of 250 meters to 1 kilometer. Relating phenology information derived from these satellites to on-the-ground observations by humans is difficult because the satellite signal integrates the response of vegetation across the entire pixel which often consists of plants and surface conditions with differing seasonality. Going forward, we expect that research challenges and opportunities in integrating phenological information across scales will increasingly involve the use of phenocams ${ }^{4}$ as an intermediate level of observational detail, as well as the use of higher-resolution (but less frequent) satellites, such as Landsat. Ground observations that are collected with an emphasis on spatial and temporal scalability and that can, therefore, inform understanding of broad-scale ecological synchronies as a result of climate drivers will also be critically needed. In addition, broad-scale assessments may be improved through the use of available hydrological, geological, and biophysical data that provide a foundation for understanding phenological variations driven by climate and land-use changes.

\section{Charter and Process for the Review}

The purpose of the USA National Phenology Network (USA-NPN) program review was

1. to assess the science utility of having a National Phenology Network;

2. to consider the USGS science mission and DOI management needs served by the USA-NPN; and

\footnotetext{
${ }^{4}$ Webcams or digital cameras used to track vegetation phenology (for an example and additional information see http://phenocam.sr.unh.edu/webcam/).
} 
3. to consider the utility of the USA-NPN to other Federal agency science missions or management needs (including the NSF and academia ${ }^{5}$ ).

USA-NPN science accomplishments to date were considered and evaluated, but the review's primary purpose was to look forward at USA-NPN science directions within the context of the USGS, DOI, and Federal science needs and to provide appropriate recommendations to senior leadership in the USGS and in the USGS Ecosystems Mission Area.

The USA-NPN (https://www.usanpn.org/) is a consortium of individuals and organizations that collect, share, and use phenology data, models, and related information. With operations started in 2007, the network is growing rapidly with respect to its contributing community, the users of its data, and its range of potential applications. Two critical entities run, lead, and advise the USA-NPN (in addition to its stakeholders): (1) the National Coordinating Office (NCO) and (2) the USA-NPN Advisory Committee.

The NCO (https://www.usanpn.org/about/staff) is based in Tucson, Arizona. The NCO is expanding its capacity and the services that it provides to the network, including national plant and wildlife phenology monitoring programs, standardized monitoring methods, an information management system, research initiatives, decision support tools, and training, education, and engagement materials. The NCO has developed a set of planning documents, including a 5-year strategic plan, 5-year and 1-year actions plans, and a risk management plan to guide USA-NPN priorities and actions over the next several years.

The USA-NPN Advisory Committee provides guidance to the NCO regarding science directions and needs of the USA-NPN and its contributors and users, both present and future. The Advisory Committee (AC) provided background materials that were based primarily on the USA-NPN workshops that were co-hosted by the AC and also provided useful feedback to the review panel on potential science directions for the USA-NPN and on the NCO's contributions to the USA-NPN. The AC's connections with the greater scientific community were particularly useful for the panel's review.

USA-NPN review panelists were Robert Cook (Oak Ridge National Laboratory), Frank Davis (University of California in Santa Barbara), Pierre Glynn (U.S. Geological Survey), David Medvigy (Princeton University), Russell Monson (University of Arizona), Bradley Reed (U.S. Geological Survey), Mark Shaffer (U.S. Fish and Wildlife Service), and David Schimel (Jet Propulsion Laboratory). Pierre Glynn and Bradley Reed served as the Panel Chair and Vice-Chair, respectively. Timothy Owen (National Oceanic and Atmospheric Administration) served as Panel Secretary. Short biographies of all the panelists are provided in appendix 1 .

The major fact-finding activity of the USA-NPN review was a 2-day workshop held in Tucson, Ariz., on April 1-2, 2014. The workshop (agenda provided in appendix 2) facilitated

\footnotetext{
${ }^{5}$ Academia refers to university research funded by the NSF and other government agencies.
}

communication between the review panel, the $\mathrm{NCO}$, the AC, and key stakeholders of the USA-NPN, including academia, Federal science and resource management agencies, and funding agencies. Several conference calls and followup activities also informed the review, including a number of action item requests that were made to the $\mathrm{NCO}$ during the workshop and which resulted in a followup report by the NCO for the review panel. In advance of the workshop and for the duration of the review process, the panel had access to a "brain box" of strategic plans, annual reports, briefs, and other documents that related to the USA-NPN and to USGS and DOI priorities. The documents made available to the panel are listed in appendix 3.

\section{USA-NPN Background Information}

This section provides a brief history of the USA-NPN and also expands further on the role of the Advisory Committee. Both are an essential preamble to the discussion and review recommendations provided by the review panel in the following sections.

\section{A Short History of the USA-NPN}

The USA-NPN has its roots in the lilac phenology monitoring network developed for the Western United States by Joseph M. Caprio of Montana State University in 1956 and extended to Eastern States by William L. Colville of the University of Nebraska and later by Mark D. Schwartz of the University of Wisconsin-Milwaukee. Spurred by a number of researchers, including Daniel Cayan and Michael Dettinger of the USGS, Mark Schwartz joined with Julio Betancourt of the USGS to propose a national network that would broaden the lilac monitoring network and extend phenological observations to a few other native and nonnative species. A key idea was that the network could potentially complement weather observations provided by the National Weather Service Cooperative Observer Program and also work in concert with other ecological monitoring networks such as (1) the National Ecological Observatory Network (NEON) and the Long-Term Ecological Research (LTER) network, (2) AmeriFlux sites, (3) USDA AgriFlux, Experimental Forest and Experimental Watershed sites, and (4) NPS Inventory and Monitoring (I\&M) sites.

Funding by the NSF helped convene a series of workshops and research coordination network meetings through which an initial implementation plan for the USA-NPN was explored in 2005 and implemented in 2006, with further improvements and planning conducted thereafter. The USA-NPN National Coordinating Office (NCO) was created in 2007 to administer USA-NPN operations and was located in Tucson, Ariz., as part of a cooperative agreement between the USGS and the University of Arizona (UA). Facilities to house the NCO were provided by UA, and UA hired the first 
Assistant Director of the USA-NPN. The USGS was responsible for hiring the Executive Director of the USA-NPN (who also leads the $\mathrm{NCO}$ ) and for providing base funds for $\mathrm{NCO}$ operations, including contractor salaries.

\section{Role of the Advisory Committee}

From its conception, the USA-NPN has sought the advice and expertise of a broad group of professionals with a vested interest in phenological information. Simultaneously with the creation of the NCO in 2007, a USA-NPN Board of Directors was formed to provide governance and to facilitate coordination across the phenology community of practice.

In 2011, the Board of Directors was reconstituted as the Advisory Committee (AC) to better serve the evolving needs of the NCO. The 15 -member AC currently provides guidance on the direction of the USA-NPN and NCO activities and identifies near-term opportunities and vulnerabilities. In addition, the $\mathrm{AC}$ works to inform the relation between USA-NPN and USGS and to help identify funding opportunities for USA-NPN and NCO activities. For example, the AC and its key members were able to obtain NSF funds that were used to hold five highly influential "Research Coordination Network" (RCN) workshops and smaller ancillary meetings between 2007 and 2012. These workshops provided national perspectives that helped focus USA-NPN needs and science directions and helped engage the academic community (and government agencies) in the USA-NPN.

\section{Discussion of the USA-NPN (by the Review Panel)}

This section and the following one containing the recommendations of the review panel were not authored by the USGS and, consequently, do not fall under the purview of USGS Fundamental Science Practices. These two sections aim to closely reflect the views expressed by the review panel rather than scientific perspectives approved by the USGS.

\section{Panel's Perspective on Accomplishments of the USA-NPN from 2007 to 2014}

The USA-NPN has done an exemplary job in promoting phenology in the United States (1) by engaging members of the public to participate as "citizen scientists" and (2) by reaching out to a diversity of governmental and nongovernmental organizations (NGO's). The National Coordinating Office (NCO) has cultivated a body of phenology data and supporting educational information and mature protocols that are broadly used in earth science research and applications. The protocols, and associated information on their use, are highly valuable because they potentially allow new participants to add information to USA-NPN databases with relatively little additional investment by the NCO. In addition, the intuitive nature of phenology lends itself to increased science awareness and literacy by the public. To this end, the NCO has developed a wealth of education/outreach materials that are congruent with the public engagement mission of USGS, DOI, and other government entities.

The NCO is also to be commended for developing a wide array of often very productive collaborations with other agencies and programs, including Federal partners, academia, and NGOs. Of particular note is the relation with NEON, which promises to increase both the quantity and quality of phenological data in the near future. The collaboration with NEON could also help the cross-scale and cross-technique integration of phenological information, from "manual" observations of individual species and phenophases, to phenocam observations, to satellite sensing of spring "green-up" and fall "brown-down."

In addition to NEON, the USA-NPN has been active in developing relations with several other partners. Appendix 4 provides an NCO perspective, through its Executive Director, of the status and potential of these partnerships as well as some metrics of accomplishments of the USA-NPN from 2007 to 2014 (with numbers recently updated to reflect May 2015 status). Appendix 5 provides a summary from the perspective of the Chair of the AC, for the period 2007 to 2014, of the accomplishments of the USA-NPN and of the contributions of the $\mathrm{AC}$ and other community members to the USA-NPN.

\section{Panel's Perspective on Risks and Needs of the USA-NPN Going Forward}

Fundamentally, phenological science and its applications are dependent on having accessible and authoritative data for useful species and phenophases with sufficient information coverage and consistency across different spatio-temporal scales. From identifying national-scale changes in seasonality to identifying risks to land management, the USA-NPN is uniquely positioned to provide a leading role because of its importance to USGS science and also because of its significant scientific and resource management relevance to many other institutions. Given limited resources, however, the USA-NPN and its NCO must focus on providing high-quality data at the national scale. ${ }^{6}$ This focus will require a shift in the balance of activities across the NCO. While education and outreach are important, so is managing a staffing profile that focuses foremost on producing the most useful scientific data and information.

${ }^{6}$ Editors' note: Bruce Jones, a reviewer of this report, comments that a national-scale dataset would be fundamentally important to the National Climate Assessment and to future North American Regional Assessments of the Intergovernmental Platform on Biodiversity and Ecosystem Services mentioned earlier. 
The foremost risk to the USA-NPN comes from the potential loss of its existing funding, which comes primarily from the USGS, if it cannot deliver the science critically needed by the USGS. The science needed from the USA-NPN includes the needs of the Ecosystems Mission area, the Climate and Land Use Change Mission Area, and several other USGS Mission Areas (Hazards, Water, Environmental Health, Core Science Systems), as discussed previously in the section on why phenology is important to the USGS and DOI. USGS science needs from the USA-NPN should align well with those of most other agencies and with the phenology needs of the broader scientific community. Going forward, demonstrating the relevance of its science, for example through partnerships with other Federal networks, should allow the USA-NPN to increase its funding from both outside and within the USGS.

There is significant interest for phenological information to help understand the fate of individual species, especially threatened and endangered species, in local ecosystems across the country. Unfortunately, it is unlikely that phenological information on a few limited species and phenophases can, by itself, provide all the needed understanding to manage a particular species in any particular locality. And even if phenology were the only factor of importance, the NCO does not have the resources to address, one by one, a multitude of diverse species and local ecosystems across the country. The first priority of the NCO, and of the USA-NPN, should be to grow and maintain its archive of long-term nationally comparable data, information that can then be translated into locally testable predictions of change for many species, and that resource management agencies could follow up on to develop further understanding on the management of any given species in a given locale. Most significantly, a focus on long-term national scale information is what will allow the USA-NPN to contribute to science and policy issues at the national and international scales. These issues include carbon cycle studies and forecasts, the parameterization of ecosystem models in Global Circulation Models, the forecasting of large-scale ecosystem disturbances (such as driven for example by sea-surface temperatures), and national climate adaptation policies. The review panel shares the view passionately expressed by one of the members of the Advisory Committee:

Local data collection focus only leads to incoherency, irrelevancy, and lack of products - which will soon lead to failure. National data collection focus provides relevancy and national-scale productstruly new scientific accomplishments which will lead to breakthroughs in understanding.

Another major risk to the USA-NPN comes from the NCO's relatively small staff with little to no duplication on critical core functions (such as data management). Additionally, the fact that the Executive Director is the only USGS employee in the NCO creates a situation in which the primary source of funding for the USA-NPN has, or could have, potentially little control over its operations.
In addition to loss of critical staff, other risks to the USA-NPN include losses to its collaborative agreements, partnerships, facilities, and equipment. The NCO is generally well aware of the risks to its operations. It recently completed a risk assessment and developed contingency plans for most of the identified risks.

\section{Review Panel Recommendations}

The order of the recommendations presented below reflects, primarily, a natural order of discussion rather than a priority of implementation. The review panel believes that the five major recommendations discussed below are important and should all be implemented.

\section{Commit to stable USA-NPN funding and increase accountability:}

\section{USGS should commit to stable USA-NPN funding of} at least $\$ 535,000$ per year for 5 years and consider a single organizational champion (e.g., Ecosystems Mission Area) for longer-term sustainment. Other USGS Mission Areas and programs that benefit scientifically from the USA-NPN should be recruited to provide additional funding. The USA-NPN National Coordinating Office (NCO) should be held accountable for demonstrating results from this funding through regular program reviews that address schedule, milestones and deliverables, and risk management. Program reviews ${ }^{7}$ should include progress toward science directions and milestones identified by a USGS-led Federal Steering Committee (see below).

\section{Establish a Federal Steering Committee led by the USGS and a separate Scientific Phenology User Group:}

The USA-NPN Advisory Committee needs to be transformed into a Federal Steering Committee (FSC) led by the USGS. ${ }^{8}$ We recommend that the Department of the Interior Solicitor's Office be consulted before this change is implemented. The new committee would provide USGS with an opportunity to take ownership of the USA-NPN and to promote its value across USGS Mission Areas and other Federal agencies. The Committee would have formal authority to advise and guide the NCO and the Executive Director. The current configuration of an external Advisory Committee has lacked the authority to guide the NCO's implementation of the USA-NPN. The new Federal Steering Committee would enable the USGS to directly guide future development of the USA-NPN and to promote its value across USGS Mission Areas and other Federal agencies.

${ }^{7}$ Editors' note: Program reviews include yearly USA-NPN progress reviews.

${ }^{8}$ The possibility of creating a Federal Advisory Committee (FAC) that would include non-Federal members was considered but rejected by the review panel because of (1) the high creation and compliance costs of a FAC relative to the current budget of the USA-NPN, and (2) the current need to increase USGS and Federal ownership (and support) of the USA-NPN. A brief description of FAC responsibilities and costs is provided in appendix 6 . 
- Clear roles and responsibilities: The FSC Chair should be a USGS manager, and the supervisor (or someone in the supervisory chain) to the NCO Executive Director should also serve as an ex-officio member on the FSC, as USGS resources and priorities allow. The Chair and the ex-officio USGS members of the Federal Steering Committee should be different individuals from two different USGS Mission Areas (e.g., Climate and Land Use Change, Water).

- The supervision of the NCO Executive Director, although within the USGS management chain, should be informed by the advice of FSC members.

- Representation from other Federal agencies: The science provided by the USA-NPN is important to many Federal agencies, as discussed previously. The FSC should be created through a Memorandum of Understanding that invites Federal agency partners to participate. Agencies invited to be represented on the FSC should include ARS (USDA), the Office of Science (Department of Energy), NASA, the NIAID (National Institutes of Health [NIH]), NOAA (Department of Commerce), NPS (DOI), NSF, USFS (USDA), and USFWS (DOI). Additionally, the FSC should consider extending invitations to the $\mathrm{CDC}$ and to NIFA (USDA), and also possibly to NIEHS (NIH), BOEM (DOI), BLM (DOI), and other agencies if the need and mutual interest arise. Each agency represented on the FSC should nominate one representative and one alternate.

USGS, through its Federal Steering Committee, should also facilitate the development of a Scientific Phenology User Group (SPUG) that includes key science and data partners for the USA-NPN. The primary role of the SPUG is to share information with the greater phenology community (including those contributing to the USA-NPN) on phenology science and applications.

- Formalize groups: The SPUG should be formally chartered with established, staggered terms of service to ensure rotation and continuity. The charter should address interactions with the FSC and the NCO. The Distributed Active Archive Center (DAAC) for Biogeochemical Dynamics, which is funded by NASA and located at Oak Ridge National Laboratory, has a User Working Group that might serve as a good model for the SPUG (cf. http://daac.ornl.gov/UWG/publicuwg. shtml).

- Align existing communities of practice: The SPUG should provide for the organization of technical user groups for a phenology-based "community of practice." In any interactions with the SPUG, the FSC should take care not to undermine the existing strength of USA-NPN as a community effort with broad investment across organizations and sectors.

- Regular information sharing: Members of the FSC, the SPUG, and key members of the NCO, as well as USGS personnel from Mission Areas with interests in the USA-NPN, should be encouraged to share information frequently and should strive to meet in person at least once a year to share information on the latest scientific developments in phenology science and accomplishments of the USA-NPN. Such a meeting could be organized within the context of a large national or international meeting such as the fall meeting of the American Geophysical Union.

\section{Emphasize continental-scale phenology data and information:}

The USA-NPN NCO needs to shift its focus to the creation of high-quality, continental-scale data and information, with USGS responsibility for data infrastructure. Although natural resource management relies on regional or even local-scale information, the ability to scale up phenological information is vital to addressing an array of environmental change science questions. Continental-scale products can take the form of weather-based algorithms for plant and animal developmental stages developed and validated with actual phenological observations and can then be mapped and assessed at regional to national scales using weather and climate reanalysis data. Related scalable products include data-fusion modeling efforts that synergistically exploit phenological ground observations and remote sensing data. Data fusion is particularly well suited for exploiting long-running USGS Landsat and other remote sensing of land surface phenology.

- Realigned NCO priorities and staffing: USGS should reevaluate the NCO staffing profile, their functions, and the overall coverage of USA-NPN and NCO needs. Recent NCO personnel changes, and the recommendations offered by the current report, make this reevaluation particularly appropriate in the near future.

- The NCO's current weighting of priorities (50 percent for Advance Science, 20 percent for Inform Decisions, and 30 percent for Communicate and Educate) needs to be revised to emphasize a predominant focus on phenological data and information collection, quality assurance, archiving, and access.

- Staff investment in data informatics and information technology is critical.

- USGS needs to take ownership of the data infrastructure associated with archive and access. 
- All nonscience activities should directly relate to the USGS' national-scale resource information mission, ${ }^{9}$ given the predominant science (versus outreach/educational focus) of the USGS.

- Best practices for data collection: Emerging datacollection options, including automated approaches, should be explored, based upon best practices for data management and data product development. These practices should reflect up-to-date standards and be consistent with international collaborations.

- NCO competition: The NCO should be periodically reviewed for prospective recompetition, renegotiation, or relocation by the USGS. Such reviews should consider possible pros (additional resources, space, and staff) and cons (instability of operation) of moving the office.

- The co-location of the NCO with the University of Arizona's School of Natural Resources and the Environment has fostered synergies between the two organizations. The research foci of the school have been beneficial to the NCO, offering opportunities for collaborative research and staff augmentation.

- USGS supervision of the NCO: The USGS should consider the possibility of having both the Executive Director and the Assistant Director of the NCO as USGS employees. This would enhance USGS supervision of the NCO.

The NCO should also focus on delivering a limited number of specific product lines that leverage its phenology holdings.

- Analysis of data coverage and collection needs: The $\mathrm{NCO}$ and the newly constituted FSC should commit to the following:

- Complete a comprehensive gap analysis to determine data coverage and collection needs for a coherent national-scale phenological database;

- Support a workshop to determine a finite suite of product lines that address key constituent needs within the USGS, DOI, and other agencies (with a particular focus on collaboration with Climate Science Centers and elsewhere in the USGS).

\footnotetext{
${ }^{9}$ Editors' note: As an agency within DOI, the USGS provides and agglomerates scientific information at the national scale that can then be used to provide national perspectives and policies on the management of natural resources, especially on Federal Lands. This national perspective can also inform resource management decisions and actions at regional and local levels.
}

- Attribution of protocols and tools to USGS needs to be strengthened.

- Current and emerging product lines: Key products should include both legacy (e.g., lilac clones) and emerging (e.g., blended satellite and in situ grids) lines.

- Densification and extension of lilac/dogwood/ etc., clone observation sites should be considered to improve significantly validation of the Spring Indices and other continental-scale, weather-based algorithms for seasonal plant development.

- These products should enhance both site-oriented and species-oriented databases using standard protocols and data capture tools to improve access and filtering capabilities.

- Extension of accessible historical phenological records: The USA-NPN should discover and ingest existing legacy data to shore up modern observations around legacy sites. Such work would help strengthen historical baselines for ongoing and future changes in seasonal timing.

- Decision tree: The NCO should prepare and follow a decision tree that tests its involvement and efforts in partnerships and outreach (current and potential) against the usefulness of their scientific data and product lines. The primary goal of the USA-NPN should be to advance science at national and long-term scales in coordination with other DOI bureaus, for example by providing and adding to Green Wave and Spring Index products and to already extensive legacy datasets rather than by focusing on products of only limited, local need.

\section{Formalize volunteer engagement in phenology data collection:}

The USA-NPN should review and implement a more structured, proactive, and directive process for volunteer involvement that contributes to nationally scaled phenology data and products. The involvement should draw on participation from other existing environmental networks.

- Leverage observer best practices: The process should be based on the best practices from other government programs (e.g., USGS Breeding Bird Survey, NOAA/ NWS/Cooperative Observer Program, Volunteer Watershed Monitoring groups) in conjunction with Citizen-Science groups and professional observers that are already making physical and biological observations as part of a larger network. 
- For example, greater efficiency in volunteer recruitment and especially retention might be improved by establishing formal agreements and more direct cooperation with other existing environmental networks. Volunteer agreements should draw on existing networks of professional observers (e.g., LTER, NEON).

- Further efforts by the NCO to leverage best practices for Citizen Science should help minimize related costs and efforts.

- Target existing observer networks for expanded phenological observations: Despite many efforts (discussed in appendix 4), the NCO has so far had limited success in recruiting existing environmental (biological or physical) networks (e.g., NWS Cooperative Observer Program, LTER, Organization of Biological Field Stations, USDA Agricultural Stations, FLUXNET sites) to make additional phenological observations that would strengthen the scientific utility and scope of the USA-NPN. The NCO (and the USA-NPN) has opportunities to build on its recent success engaging NEON and should strive to recruit other scientific observation networks. The goal should be to bring in data on a select and limited number of species that form a national core of observations and serve compelling long-term and continental-scale objectives.

\section{Integrate phenology information into USGS science:}

Phenology is an integrative science that cuts across many traditional scientific disciplines and that has relevance to six of the seven USGS Mission Areas. One Mission Area in the USGS should be identified to be the champion for phenology science and for the USA-NPN. However, active interest, financial participation, and leveraging of scientific resources should be strongly encouraged from the five other relevant Mission Areas (cf. discussion in the "Background" section). In addition, the USA-NPN has critical geospatial information needs that could best be met by programmatic and infrastructure support from the USGS Core Science Systems Mission Area.

- Proactive data integration: The USGS should proactively integrate phenology information, including applications in ecosystems, climate and land-use change, natural hazards (fire and drought), and environmental health.

- Infrastructure support: The USGS should offer relevant Information Technology solutions for preservation and accessibility of USA-NPN information.
- For example, work with the USGS Land Remote Sensing (LRS) Program fusing Landsat and Spring Index work.

- Data should readily be backed up using cloud technologies.

\section{Acknowledgments}

The editors thank Bruce Jones (Desert Research Institute), Robert Hirsch (USGS), Geoffrey Henebry (South Dakota State University), Jake F. Weltzin (USGS), David Inouye (University of Maryland), Wendy Norton (USGS), and Shawn Carter (USGS) for their reviews and comments on the report. Sections of the report that are identified as representing the perspectives or recommendations of the review panel were not subject to USGS Fundamental Science Practices (and therefore to USGS technical review), because those perspectives and recommendations were not authored by USGS scientist(s). The editors also thank Kevin Breen for his thoughtful consideration and clarification of USGS policy in the publication of this report.

\section{References Cited}

Ault, T.R., Schwartz, M.D., Zurita-Milla, R., Weltzin, J.F., and Betancourt, J.L., in press, Trends and natural variability of spring onset in the coterminous United States as evaluated by a new gridded dataset of spring indices: Journal of Climate [accepted June 25, 2015].

Leopold, A., and Jones, S.E., 1947, A phenological record for Sauk and Dane Counties, Wisconsin, 1935-1945: Ecological Monographs, v. 17, no. 1, p. 81-122.

U.S. Department of Agriculture, 2008, Forest Service strategic framework for responding to climate change (ver. 1.0): U.S. Department of Agriculture, Forest Service, 21 p., accessed April 9, 2015, at http://www.fs.fed.us/ climatechange/documents/strategic-framework-climatechange-1-0.pdf.

U.S. Department of Agriculture, 2011, National roadmap for responding to climate change: U.S. Department of Agriculture, Forest Service, FS-957b, 32 p., accessed April 27, 2015, at http://www.fs.fed.us/climatechange/ pdf/roadmap.pdf. 
Appendixes 1-6 


\section{Appendix 1. Panel Member Biographies}

Robert Cook (email: cookrb@ornl.gov; profile) is a research staff member with the NASA-funded Distributed Active Archive Center at Oak Ridge National Laboratory. The center provides data and information relevant to biogeochemical dynamics, ecological data, and environmental processes, critical for understanding the dynamics relating to the biological, geological, and chemical components of the Earth's environment. Dr. Cook is also co-principal investigator for DataONE (Observation Network for Earth), a National Science Foundation-funded cyberinfrastructure that seeks to promote science and education through straightforward access to Earth observation data spanning broad science disciplines. His research interests include biogeochemistry, global change, integrated assessments, aqueous geochemistry, transport and fate of contaminants in aquatic ecosystems, and water resources management.

Frank Davis (email: fwd@bren.ucsb.edu; profile) is Professor of Landscape Ecology and Conservation Planning at the University of California, Santa Barbara (UCSB), where he also serves as the Director of the National Center for Ecological Analysis and Synthesis. He heads the Biogeography Lab at the Bren School of Environmental Science and Management at UCSB. His research focuses on the landscape ecology of California plant communities, the design of protected-area network, rangeland and farmland conservation, and the biological implications of regional climate change.

Pierre Glynn (email: pglynn@usgs.gov; profile) is Chief of the Eastern Branch of the National Research Program at the U.S. Geological Survey. He oversees a broad diversity of science in areas such as numerical modeling of water flow and solute transport, environmental isotope forensics and characterization, groundwater dating, water and sediment contamination problems, nutrient cycling, ecological habitats, geomorphic processes, and the application of molecular and other techniques to the study of microbial processes. His current interests include integrated environmental modeling, Citizen Science, watershed research and monitoring programs, and the behavioral biogeosciences.

David Medvigy (email: dmedvigy@princeton.edu; profile) is Assistant Professor in the Department of Geosciences at Princeton University. His research focuses on understanding local-regional scale variability in climate and terrestrial biosphere, with a focus on the processes linking these two components of the Earth system. His research includes study of the relations between the atmospheric circulation, terrestrial ecology, and biogeochemical fluxes, and how all of these are responding (and are projected to respond) to anthropogenic forcings. His laboratory addresses these issues through numerical models, including variableresolution general circulation models, mesoscale meteorological models, and mechanistic models of ecosystem composition, structure, and functioning.

Russ Monson (email: russmonson@email.arizona.edu; profile) is Louise Foucar Marshall Professor at the University of Arizona, Tucson, and Professor Emeritus at the University of Colorado, Boulder. His research focuses on photosynthetic metabolism, the production of biogenic volatile organic compounds, and plant water relations from the scale of chloroplasts to the globe. He is particularly interested in how climate change in the Western United States is influencing the carbon and water cycles in mountain forests. $\mathrm{He}$ has received numerous awards, including the Alexander von Humboldt Fellowship, the John Simon Guggenheim Fellowship, and the Fulbright Senior Fellowship, and was also appointed Professor of Distinction in the Department of Ecology and Evolutionary Biology at the University of Colorado.

Timothy Owen (email: tim.owen@noaa.gov) is Operations Officer for the Climate Services Division at the National Oceanic and Atmospheric Administration's National Climatic Data Center (NCDC). Since starting there as a student in 1990, he has worked on a variety of projects, including climate data validation, urban heat island research, climate normals generation, climate applications using GIS, and the start of drought.gov - the Web portal of the National Integrated Drought Information System. His past research has included satellite studies of urban regions and environmental planning for park viewsheds. In recent years, he has served as NCDC's National Partnership Liaison and Executive Officer and has provided input to both the 2007 IPCC and 2009 Climate Change Impacts reports. Mr. Owen is also an adjunct professor in the Department of Atmospheric Sciences at the University of North Carolina at Asheville. He also currently serves the phenology scientific community as NOAA representative on the USA-NPN Advisory Committee.

Bradley Reed (email: reed@usgs.gov) has been the Associate Program Coordinator for the Land Change Science Program at USGS headquarters in Reston, Virginia, since 2008. He works on the national assessment of biological carbon sequestration and the use of this information for decision makers. He began his career as an Assistant Professor at New Mexico State University's Department of Earth Sciences and then took a research position at the U.S. Geological Survey's Earth Resources Observation and Science (EROS) Center. He was a member of the team that completed the first conterminous U.S. land cover dataset using satellite remote sensing and then led the team that 
completed the first global land cover dataset from remote sensing data (IGBP DISCover). Dr. Reed received his Ph.D. in Geography with an emphasis in remote sensing and a minor in Physiological Plant Ecology. He has worked on satellite remote sensing of phenology since the early 1990s.

David Schimel (email: David.Schimel@jpl.nasa.org; profile) is a Senior Scientist with the NASA-funded Jet Propulsion Laboratory (JPL) at the California Institute of Technology in Pasadena, California. He serves as Lead Scientist for the Carbon and Ecosystems program at JPL. His research interests include global biogeochemical cycles, traces gases, and climate modeling. He was a Convening Lead Author of the 2007 report by the IPCC that won a Nobel Peace Prize. Prior to coming to JPL, Dr. Schimel served as Principal Investigator, Chief Science Officer, and Chief Executive Officer for the NSF-funded National Ecological Observatory Network (NEON). He also held distinguished positions at the National Center for Atmospheric Research in Boulder, Colorado, and at the Max-Planck Institute for Biogeochemistry (Germany), where he served as Founding Director. Dr. Schimel is a Fellow of the Ecological Society of America and of the American Geophysical Union.
Mark Shaffer (email: mark_shaffer@fws.gov) is National Climate Change Policy Advisor, Office of the Science Advisor, with the U.S. Fish and Wildlife Service in Arlington, Virginia. He is a biodiversity conservationist with extensive experience in population viability analysis, conservation biology, resource economics, and environmental philanthropy. As Program Director for the Environment at the Doris Duke Charitable Foundation, he provided strategic direction for the investment of nearly $\$ 100$ million in land conservation projects and promoted the implementation of state wildlife action plans. The Foundation's investments have assisted in the conservation of nearly 2 million acres of high priority habitat nationwide. As Senior Vice President of Programs for Defenders of Wildlife, Dr. Shaffer provided direction, oversight, and administration of the organization's species, habitat, and legal work, while managing a regional staff in eight states. Prior to his work with Defenders of Wildlife, Dr. Shaffer worked with three other major conservation organizations: The Nature Conservancy, The Wilderness Society, and the U.S. Fish and Wildlife Service. Dr. Shaffer's doctoral research on grizzly bears helped to pioneer population viability analysis in conservation biology. 


\section{Appendix 2. Agenda and Attendees of the April 2014 Review Workshop}

Date: April 1-2, 2014

Location: University of Arizona Student Union and Tucson Marriott University Park, Tucson, Arizona

Note: Participants and speakers who were invited but unable to attend are listed in brackets and (or) marked absent. All times listed are for the Arizona Time Zone unless otherwise identified.

Day 1 (Tuesday, April 1)

Review of Existing Structure and Plans-Open to all participants

8:00-9:45 (Santa Cruz Room, University of Arizona Student Union, 3rd floor)

Introductions (30 minutes)

- Welcome-Stuart Marsh, Director, School of Natural Resources and the Environment, University of Arizona (10 minutes)

- Introduction -Pierre Glynn, Chief, National Research Program/Eastern Branch, USGS (5 minutes)

- Logistics—Jake Weltzin, Executive Director, USA-NPN, USGS, and workshop host (5 minutes)

- Round-robin introductions for all workshop participants (10 minutes)

Framing the workshop: Purpose in the context of the Program Review (15 minutes)

- 8:30 (11:30 EDT) William Lellis, Deputy Associate Director, Ecosystems Mission Area, USGS (10 minutes, remote)

- 8:40 Pierre Glynn, USGS (5 minutes)

The Potential of Phenology as an Integrative Environmental Science (60 minutes)

- 8:45 Geoffrey Henebry, Professor of Natural Resource Management, South Dakota State University and Chair, USA-NPN Advisory Committee (20 minutes including Q\&A, in person)

- 9:05 (12:05 EDT) Andrew Richardson, Associate Professor of Organismic and Evolutionary Biology, Harvard (20 minutes including Q\&A, remote)

- 9:25 (12:25 EDT) Toby Ault, Assistant Professor of Earth and Atmospheric Sciences, Cornell (20 minutes including Q\&A, remote)

9:45-10:00 Break (15 minutes)

10:00-11:50 Science, Applications and Operations of USA-NPN (110 minutes)

- Introduction to the USA-NPN: Current status and future directions-Jake Weltzin (40 minutes including 10 minutes clarification questions)

- Providing support for research and engagement at the National Park Service—Katharine Gerst, Assistant Research Scientist, USA-NPN NCO (15 minutes including 3 minutes clarification questions)

- Providing capacity to USFWS: Valle de Oro case study_Erin Posthumus, U.S. Fish and Wildlife Service Liaison and Outreach Associate, USA-NPN NCO (15 minutes including 3 minutes clarification questions)

- Plenary Q\&A and discussion - Facilitated by Pierre Glynn, USGS (40 minutes) 
11:50-12:50 Lunch at restaurants in Student Union (60 minutes)

12:50-3:00 USA-NPN—Stakeholders Speak (130 minutes)

- 12:50 (3:50 EDT) Jana Newman, National Inventory and Monitoring Manager, National Wildlife Refuge System Inventory and Monitoring Program, USFWS (20 minutes including Q\&A, remote)

- 1:10 (4:10 EDT) Steve McNulty, Director, USDA SE Climate Hub, USFS (20 minutes including Q\&A, remote)

- 1:30 (2:30 MDT) Brian Wee, Chief of External Affairs, National Ecological Observatory Network (NEON) [and Liz Blood, Program Officer, National Ecological Observatory Network, National Science Foundation] [ABSENT] (total of 30 minutes including Q\&A, remote)

- 2:00 (3:00 MDT) John Gross, Ecologist, NPS and USA-NPN Advisory Committee Member (20 minutes including Q\&A, remote)

- 2:20 Jeff Morisette, Director North Central Climate Science Center, USGS (20 minutes including Q\&A, in person)

- 2:40 (2:40 PDT) Susan Mazer, Professor of Ecology \& Evolution, U California Santa Barbara and USA-NPN Advisory Committee Member (20 minutes including Q\&A, remote)

3:00-3:20 Break (20 minutes)

3:20-4:30 Open Discussion on status and directions of USA-NPN (70 minutes) (Facilitated by Pierre Glynn, USGS)

4:30 Adjourn

Day 2 (Wednesday, April 2)

\section{Panel Investigations-Panel, NCO, and select invitees only}

Morning Location: Santa Cruz Room, University of Arizona Student Union (3rd floor)

8:00-8:30 Questions and answers by Panel to NCO or select invitees (30 minutes) (Facilitated by Pierre Glynn, USGS)

- Panel queries for clarification of prior presentations, or to obtain additional information about USA-NPN

- Discussion/clarification of seminal documents provided for the review

- Discussion of USA-NPN within the context of the USGS Mission (and above)

- Process, information, and input needs for going forward to Phase 3 of the review process

\section{8:30-9:00}

- 8:30 (11:30 EDT) Healy Hamilton, Chief Scientist and Vice President for Conservation Science, NatureServe (30 minutes including Q\&A, remote)

\section{9:00-9:30}

- [Katharine Jacobs, Professor, Department of Soil, Water and Environmental Science, University of Arizona and Assistant Director, Climate Adaptation \& Assessment, White House Office of Science \& Technology Policy (30 minutes including Q\&A, in person)] [ABSENT]. Time slot devoted to an extension of the earlier Q\&A with the NCO and other invitees (Facilitated by Pierre Glynn, USGS) 
9:30-9:35 Break (5 minutes)

9:35-10:10 Panel/AC Discussion—Only for panel members and Geoff Henebry (35 minutes)

- AC perspective on the USA-NPN

- Process, information, and input needs for going forward to Phase 3 of the review process

10:10-10:20 Break (10 minutes)

10:20-11:30 Field trip to participate in phenology monitoring (70 minutes)

- University of Arizona Krutch Garden (3 minute walk from Student Union)

11:30-12:30 Lunch (60 minutes)

Afternoon Location: Laboratory of Tree Ring Research, 4th floor Conference Room

\section{2:30-2:30 Panel Discussion-Panel Only}

- Led by Pierre Glynn, USGS

- Revisit purpose and charge to Panel

- Define structure of report

- Identify additional information needs

- Written documentation, figures, tables, etc.

- Personal communication, such as followup phone calls

- Identify individual tasks

- Identify timeline

\section{2:30-3:30 Presentation of initial Panel recommendations to Jake Weltzin and Alyssa Rosemartin}

\section{Workshop information and logistics}

- Workshop information (agenda, reading materials, presentations) posted at a password-protected Web page: https://www.usanpn.org/2014-review (facilitated by Sara Schaffer, NCO)

- Attendees were asked to become familiar with the USA-NPN Web page (http://www.usanpn.org) and Nature's Notebook (http://www.usanpn.org/natures_notebook) 


\section{Workshop Organization Committee}

Pierre Glynn, USGS, Review Panel Chair Bradley Reed, USGS, Review Panel Vice-Chair Jake Weltzin, USGS, NCO Executive Director Alyssa Rosemartin, University of Arizona (UA), NCO Assistant Director, Workshop Host Sharon Oliver, NCO, Logistics Coordinator Timothy Owen (NOAA; Review Panel Secretary)

\section{Workshop Attendee List Review Panel}

Pierre Glynn, USGS, Chair

Bradley Reed, USGS, Vice-Chair

Bob Cook, ORNL

Frank Davis, NCEAS

David Medvigy, Princeton

Russ Monson, UA

David Schimel, JPL

Mark Shaffer, USFWS

\section{USA-NPN NCO}

Jake Weltzin, USA-NPN, USGS

Alyssa Rosemartin, USA-NPN, UA

Carolyn Enquist, USA-NPN, UA

Theresa Crimmins, USA-NPN, UA

LoriAnne Barnett, USA-NPN, UA

Ellen Denny, USA-NPN, UA

Katharine Gerst, USA-NPN, UA

Patricia Guertin, , USA-NPN, UA

Lee Marsh, USA-NPN, UA

Sharon Oliver, USA-NPN, UA

Erin Posthumus, USA-NPN, UA

Sara Schaffer, USA-NPN, UA

\section{Review Panel Secretary/Rapporteur}

Tim Owen, NOAA-NCDC (with Sharon Oliver as backup)

Speakers (all remote unless otherwise indicated)

Toby Ault, Cornell

Liz Blood, NSF (absent; represented by Brian Wee)

John Gross, NPS

Healy Hamilton, NatureServe

Geoff Henebry, SDSU (in person)

Katharine Jacobs, UA (absent)

William Lellis, USGS

Stuart Marsh, UA (in person)

Jeff Morisette, USGS (in person)

Susan Mazer, UC Santa Barbara

Steve McNulty, USDA-USFS

Jana Newman, USFWS

Andrew Richardson, Harvard

Brian Wee, NEON (in person)

Other Invited Attendees From UA And USGS Community

Matthew Andersen, USGS (absent)

Douglas Beard, USGS NCCWSC (absent)

Shawn Carter, USGS NCCWSC (in person)

Steve Jackson, USGS, NCCWSC SWCSC (in person)

Anne Kinsinger, USGS (absent)

Matthew Larsen, USGS (absent)

David Lytle, USGS SBSC (absent)

David Moore, UA SNRE (in person)

Sarah Ryker, USGS (absent)

Charles van Riper, USGS SBSC SDRS (in person) 


\section{Appendix 3. List of Documents Provided to the Review Panel}

The following list provides hyperlinked access to USA-NPN documents and informational Web sites provided to the panel:

- Review Process and Charge - distributed by Pierre Glynn on 1/17/14

- Program Review Teleconference One Notes (1/17/14)

- Program Review Teleconference Two Notes (2/13/14)

- Final Workshop Agenda

- USA-NPN Fiscal Year 07-14 Budget: pdf file and Excel file

- USA-NPN Attributed Publications and USA-NPN publications link (https://www.usanpn.org/pubs/results)

- History of USA-NPN

- USA-NPN 2012 Research Coordination Network Workshop Report

- USA-NPN 2012 Annual Report

- USA-NPN 2013 Annual Report

- USA-NPN FY2014 Action Plan
USA-NPN Planning and Implementation Documents:

- Towards a USA National Phenology Network

- Funded NSF Research Coordination Network Proposal

- USA-NPN 5-year Strategic Plan (January 2014 draft)

Other General Documents:

- DOI, USGS, and Ecosystems Priorities

- Ecosystems Mission Area Strategic Science Plan and Executive Summary

- DOI Secretarial Priorities (Sally Jewell, October 2013)

- Web link: Search all USA-NPN Partner Organizations

Additional information provided for the USA-NPN review included workshop presentations, a confidential 2013 USA-NPN risk management report, confidential opinions from the AC (Chair and members) and the NCO (Executive Director and staff), and various USA-NPN statistics and information provided by the USA-NPN in response to requests. Additionally, USGS Mission Area strategic plans were mentioned through their Web link (http://www.usgs.gov/ start_with_science/). 


\section{Appendix 4. National Coordinating Office Perspective of USA-NPN Accomplishments Since 2007}

\author{
By Jake F. Weltzin, USA-NPN National Coordinating Office \\ (NCO) Executive Director
}

\section{Status of Key USA-NPN Partnerships (Numbers Updated to May 2015)}

The National Ecological Observatory Network (NEON), when fully implemented by 2017 , will have 60 permanent sites for multiplatform monitoring of plant phenology using USA-NPN published protocols, and will contribute approximately 750,000 records to USA-NPN each year through Application Program Interfaces (API). As of 2014, 13 sites were monitoring phenology. NEON in situ observations of plant phenology can be linked to cameras and remote sensing, carbon flux, and climatology. The USA-NPN NCO and NEON have a standing Data Product Working Group to discuss development and delivery of data products and QA/ QC methodologies.

The National Park Service (NPS), a DOI Bureau, uses the USA-NPN protocols and Information Management System at 24 park units (including parks, Research Learning Centers, and Inventory and Monitoring Program regions) across the Nation to meet goals related to resource management and engagement. Since 2009, collaborations between the USA-NPN and NPS Inventory and Monitoring have been guided by a written conceptual framework (http://www. usanpn.org/nps). On the basis of this framework, NPS and NCO have created multiple cooperative agreements totaling $\$ 180,000$ to date, and the NCO has contributed to the development of two formal published NPS Monitoring Protocols. The NCO has also collaborated with two regional NPS pilots, the California Phenology Project (https://www.usanpn.org/ cpp/) and the Appalachian Trail Seasons project (https://www. usanpn.org/appalachian/).

The National Wildlife Refuge System (NWRS) of the U.S. Fish and Wildlife Service (a DOI Bureau) uses USA-NPN protocols and the Information Management System at 14 units across the Nation to meet a variety of goals related to resource management and engagement (https://www. usanpn.org/fws/). A conceptual framework for collaboration between the NCO and the NWRS Inventory and Monitoring Program has been in place since 2012. Multiple intra-agency agreements total $\$ 500,000$ to date.

The Long-term Ecological Research (LTER) Network is a distributed national network of 26 quasi-independent research sites that are funded by the National Science Foundation and that have dedicated land and infrastructure for visiting scientists and students. A Memorandum of Understanding between the NCO and the LTER Network Office was established in 2008 (https://www.usanpn.org/lter). A preliminary summary analysis of all LTER phenology datasets has been completed, and data for several sites are being contributed, including H.J. Andrews, Cedar Creek Natural History Area, Jornada Experimental Range, Baltimore Ecosystems Study, and the Phoenix Urban Site. Some of these sites are being used to develop tools to cross-walk historical phenology data to the contemporary (USA-NPN) protocols. NCO staff have given presentations at two triennial All-Scientist Meetings since 2007, and we continue to explore opportunities for cross-site synthesis of phenology datasets.

The Long-term Agroecosystem Network (LTAR) is being established by the Agricultural Research Service (ARS). LTAR is a nascent, national applied observing network with at least 18 fully instrumented sites across a variety of agroecosytems, including experimental watersheds, forests and rangelands, and row-crop agroecosytems, several of which are co-located with NEON and LTER sites. LTAR developers are interested in incorporating phenology monitoring into their experimental design. Data are already being collected at several LTAR sites, including the Jornada Experimental Range (JER), the Santa Rita Experimental Range, and the Central Plains Experimental Range. JER already has 4 years of pilot data that were collected using USA-NPN protocols. The NCO is collaborating with the LTAR Science Advisory Committee to develop a MOU and a scope of work for an agreement to transfer resources from the USDA to the University of Arizona to support the collaboration, including the development of new standardized phenology monitoring protocols for agricultural species.

The National Weather Service Cooperative Observer Program (in the Department of Commerce, National Oceanic and Atmospheric Administration, National Climatic Data Center [NCDC]) is a national network of volunteer weather observers who are familiar with monitoring. The NCO has pursued a collaboration with the Cooperative Observer Program since 2007, because of the potential to link in situ phenology data to meteorological conditions and, over time, climate. NCDC recently placed a link to USA-NPN on their WXCoder page (where co-op observers submit their data), which to date has resulted in hundreds of registrants to Nature's Notebook that self-identify as members of the Cooperative Observer Program.

The Organization of Biological Field Stations (OBFS) is a distributed international network of about 500 independent field stations with dedicated land and infrastructure for scientists, educators, and students. The Network includes important subnetworks such as the University of California Natural 
Reserve System (UC-NRS). The NCO already interacts with many members of OBFS, including the Great Basin Bird Observatory, the Palomarin Field Station, the Merriam-Powell Field Station, the MacLeish Field Station, Pepperwood Preserve, Rocky Mountain Biological Laboratory, Cedar Creek Natural History Area, and at least seven UC-NRS sites. NCO staff have given or contributed to at least five presentations at OBFS annual meetings since 2007.

USDA Cooperative Extension, situated at Land-Grant Universities across the Nation, is the institutional home for quasi-independent chapters of Master Naturalists and Master Gardeners. The NCO has created active collaborations with Cooperative Extensions in Arizona, Florida, Ohio, New Mexico. Oregon, Utah, Minnesota, Virginia, and Washington and is working with several sites, such as the Ohio State University network of 48 monitoring sites, to standardize data collection and to integrate local data into the National Phenology Database. The USA-NPN is featured on the national Web page of Master Naturalists, and NCO staff have contributed to a number of Cooperative Extension publications about phenology and phenology monitoring.

Signs of the Seasons - A New England Phenology Project is a multiyear project initiated, developed, and maintained by the University of Maine Cooperative Extension and NOAA Sea Grant. This project, which leverages on the capacity provided by the USA-NPN, was originally a state-level project that is in the process of expanding to the New England region. There are about 200 Signs of the Seasons observers registered as participants with Nature's Notebook.

At least 17 botanical gardens and arboreta across the Nation are tracking phenology using Nature's Notebook. To coordinate with these organizations, NCO staff have given presentations at three recent American Public Gardens Association meetings.

\section{Metrics Of USA-NPN Accomplishments and Outcomes}

\section{Key Accomplishments Since 2007 Include (Numbers Updated to May 2015)}

- Standardized Protocols - at least 70 suites of relevant, easy-to-observe phenophases developed, defined, published, and applied to 1,016 species.

- Information Management System-database; tools for data input, output, and visualization including custom Web application and mobile applications; metadata; machine-readable data-sharing; legacy data integration and delivery; information-rich Web site and documentation; terms of use; Federal compliance.

- Observer Base - over 5,000 active observers recruited and retained, and 206 groups participating in data collection; communication and education framework developed to garner long-term, high-quality data.
- Data Products - raw data dynamically delivered online; six annual multitaxa datasets with metadata and DOIs available via DataONE; upgraded pheno-climate model (SI-x); other products in pipeline.

\section{Key Outcomes Since 2007 Include (Numbers as of May 2015)}

- Adoption and field-testing of protocols across a diversity of partners, disciplines, and ecoregions (e.g., NEON, NPS, USFWS).

- A contemporary dataset (www.usanpn.org/data/dashboard) with more than 5.2 million records (fig. 4-1) and more than 7,200 active observation locations across the Nation (fig. 4-2).

- An average of 850 unique queries per month of the data download tool.

- Since 2007, thirteen peer-reviewed publications that rely on contemporary data and 12 peer-reviewed publications that rely on legacy lilac data (see lists below collected through the Nature's Notebook observing system); a total of 131 publications (https://www.usanpn. $\mathrm{org} / \mathrm{pubs} /$ results)are attributed to the activities of the USA-NPN since 2007.

\section{Publications that Rely on Contemporary Data from the National Phenology Database}

Chapman, D.S., Haynes, T., Beal, S., Essl, F., and Bullock, M., 2014, Phenology predicts the native and invasive range limits of common ragweed: Global Change Biology, v. 20, no. 1, p. 192-202.

Crimmins, T.M., Weltzin, J.F., Rosemartin, A., Surina, E.M., Marsh, L.R., and Denny, E.G., 2014, Focused campaign increases activity among participants in Nature's Notebook, a citizen science project: Natural Sciences Education, v. 43, no. 1, p. 64-72.

Euskirchen, E.S., Carman, T.B., and McGuire, A.D., 2013, Changes in the structure and function of northern Alaskan ecosystems when considering variable leaf-out times across groupings of species in a dynamic vegetation model: Global Change Biology, v. 20, no. 3, p. 963-978.

Fu, Y.H., Piao, S., Vitasse, Y., Zhao, H., DeBoeck, H.J., Liu, Q., Yang, H., Weber, U., Hänninen, H., and Janssens, I.A., 2015, Increased heat requirement for leaf flushing in temperate woody species over 1980-2012-Effects of chilling, precipitation and insolation: Global Change Biology, accessed May 1, 2015, at http://dx.doi.org/10.1111/ gcb. 12863 .

Fuccillo, K.K., Crimmins, T.M., deRivera, C.E., and Elder, T.S., 2014, Assessing accuracy in volunteer-based plant phenology monitoring: International Journal of Biometeorology, http://dx.doi.org/10.1007/s00484-014-0892-7. 
Jeong, S.J., and Medvigy, D., 2014, Macroscale prediction of autumn leaf coloration throughout the continental United States: Global Ecology and Biogeography, v. 23, no. 11, p. $1245-1254$.

Jeong, S.J., Medvigy, D., Shevliakova, E., and Malyshev, S., 2013, Predicting changes in temperate forest budburst using continental-scale observations and models: Geophysical Research Letters, v. 40, no. 2, p. 359-364.

Kellermann, J.L., Enquist, C.A.F., Humple, D.L., Seavy, N.E., Rosemartin, A., Cormier, R.L., and Barnett, L.A., 2015, A bird's-eye of the USA National Phenology Network-An off-the-shelf monitoring network, in Wood, E.M., and Kellermann, J.L., eds., Phenological synchrony and bird migration - Changing climate and seasonal resources in North America (Studies in avian biology series, no. 47): Boca Raton, Fla., CRC Press, p. 47-60.

Liang L., and Schwartz, M.D., 2014, Testing a growth efficiency hypothesis with continental-scale phenological variations of common and cloned plants: International Journal of Biometeorology, v. 58, p. 1789-1797.

McCormack, M.L, Gaines, K.P., Pastore, M., and Eissenstat, D.M., 2015, Early season root production in relation to leaf production among six diverse temperate tree species: Plant and Soil, v. 389, no. 1-2, p. 121-129, http://dx.doi. org/10.1007/s11104-014-2347-7.

Medvigy, D., Jeong, S.J., Clark, K.L., Skowronski, N.S., and Schäfer, K.V.R., Effects of seasonal variation of photosynthetic capacity on the carbon fluxes of a temperate deciduous forest: Journal of Geophysical Research-Biogeosciences, v. 118, no. 4, p. 1703-1714.

Rosemartin, A.H., Crimmins, T.M., Enquist, C., Gerst, K.L., Kellerman, J.L., Posthumus, E.E., Weltzin, J.F., Denny, E.G., Guertin, P., and Marsh, L.R., 2014, Organizing phenological data resources to inform natural resource conservation: Biological Conservation, v. 173, p. 90-97, http:// dx.doi.org/doi:10.1016/j.biocon.2013.07.003.

Yue, X., Unger, N., Keenan, T.F., Zhang, X., and Vogel, C.S., 2015, Probing the past 30 year phenology trend of US deciduous forests: Biogeosciences Discussions, v. 12, p. 6037-6080, paper accessed April 30, 2015, under Open Access Review at http://www.biogeosciences-discuss. net/12/6037/2015/.

\section{Publications that Rely on Legacy Data from the National Phenology Database}

Ault, T.R., Henebry, G.M., de Beurs, K.M., Schwartz, M.D., Betancourt, J.L., and Moore, D., 2013, The false spring of 2012, Earliest in North American record: Eos Transactions American Geophysical Union, v. 94, no. 20, p. 181-182.

McCabe, G.J., Ault, T.R., Cook, B.I., Betancourt, J.L., and Schwartz, M.D., 2012, Influences of the El Niño South- ern Oscillation and the Pacific Decadal Oscillation on the timing of North American spring: International Journal of Climatology, v. 32, no. 15, p. 2301-2310, http://dx.doi. org/10.1002/joc.3400.

McCabe, G.J., Betancourt, J.L., Pederson, G.T., and Schwartz, M.D., 2013, Variability common to first leaf dates and snowpack in the western conterminous United States: Earth Interactions, v. 17, p. 1-18.

Peterson, A.G., and Abatzoglou, J.T., 2014, Observed changes in false springs over the contiguous United States: Geophysical Research Letters, v. 41, no. 6, p. 2156-2162.

Piao, S., Tan, J., Chen, A., Fu, Y.H., Ciais, P., Liu, Q., Janssens, I.A., Vicca, S., Zeng, Z., Jeong, S.-J., Li, Y., Myneni, R.B., Peng, S., Shen, M., and Penuelas, J., 2015, Leaf onset in the northern hemisphere triggered by daytime temperature: Nature Communications, v. 6, article 6911, accessed May 1, 2015, at http://dx.doi.org/10.1038/ncomms7911.

Schwartz, M.D., Betancourt, J.L., and Weltzin, J.F., 2012, From Caprio's lilacs to the USA National Phenology Network: Frontiers in Ecology and the Environment, v. 10, no. 6, p. 324-327.

Schwartz, M.D., and Hanes, J.M., 2010, Continental-scale phenology - Warming and chilling: International Journal of Climatology, v. 30, no. 11, p. 1595-1598.

Schwartz, M.D., and Hanes, J.M., 2010, Intercomparing multiple measures of the onset of spring in eastern North America: International Journal of Climatology, v. 30, no. 11, p. 1614-1626.

Schwartz, M.D., Hayhoe, K., Wake, C., Huntington, T.G., Luo, L., Sheffield, J., Wood, E., Anderson, B., Bradbury, J., DeGaetano, A., Troy, T.J., and Wolfe, D., 2007, Past and future changes in climate and hydrological indicators in the U.S. Northeast: Climate Dynamics, v. 28, no. 4, p. 381-407.

Schwartz, M.D., Kathuroju, N., White, M.A., Symanzik, J., Powell, J.A., and Nemani, R.R., 2007, On the use of the advanced very high resolution radiometer for development of prognostic land surface phenology models: Ecological Modelling, v. 201, no. 2, p. 144-156.

White, M.A., de Beurs, K.M., Didan, K., Inouye, D.W., Richardson, A.D., Jensen, O.P., O'Keefe, J., Zhang, G., Nemani, R.R., van Leeuwen, W.J.D., Brown, J.F., de Wit, A., Schaepman, M., Lin, X., Dettinger, M., Bailey, A., Kimball, J., Schwartz, M.D., Baldocchi, D.D., Lee, J.T., and Lauenroth, W.K., 2009, Intercomparison, interpretation, and assessment of spring phenology in North America estimated from remote sensing for 1982 to 2006: Global Change Biology, v. 15 , no. 10 , p. $2335-2359$.

Zhang, X., Tarpley, D., and Sullivan, J.T., 2007, Diverse responses of vegetation phenology to a warming climate: Geophysical Research Letters, v. 34, no. 19, http://dx.doi. org/10.1029/2007GL031447. 


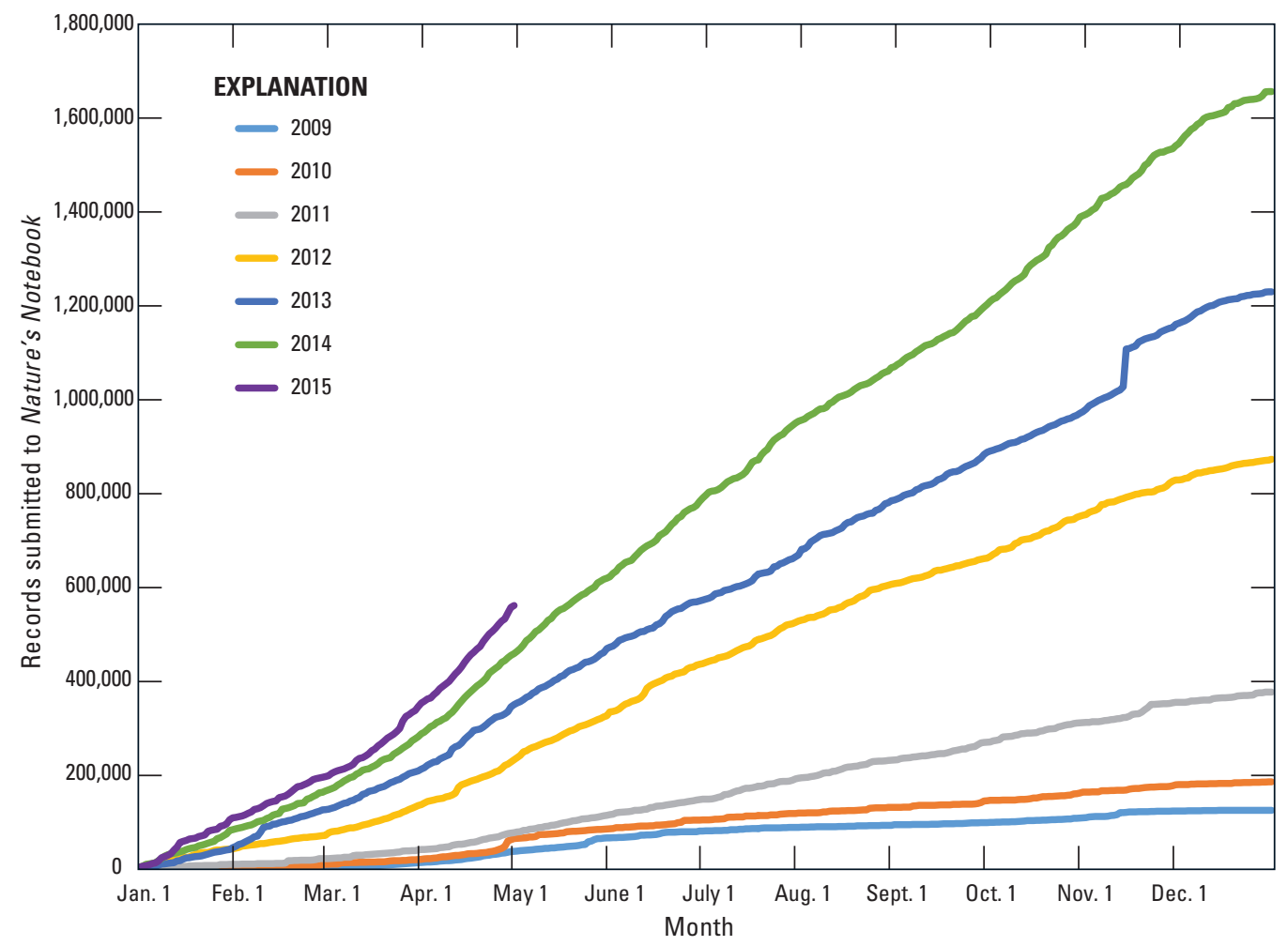

Figure 4-1. Annual accumulation of records submitted via Nature's Notebook to the USA-NPN National Phenology Database from January 2009 through May 2015. Total annual records can be determined from the end of each line on the right side of the panel. Each year, the total number of records, and the rate of the contribution of records, has increased. Records accumulated at a rate of 19,912 $\pm 13,290$ (records/month \pm 1 standard deviation) during 2009-2011; 86,940 $\pm 33,077$ in 2012-2013; and 129,420 \pm 48,866 in 2014-2015. Intra-annual variations reflect relatively low activity during the winter months (when slopes are relatively low) and an increase in activity each spring, with a relatively constant contribution of records through the growing season. The increase in number of records in May 2010 reflects the inclusion of records from the historical national lilac and honeysuckle monitoring program. The large jump in rates and number of records in 2012 relative to prior years reflects an increased effort in marketing the program to potential partners by the NCO and includes data contributed by the National Park Service and the California Phenology Project.

Figure 4-2 (facing page). Spatial distribution of records by registered Nature's Notebook site submitted to the USA-NPN National Phenology Database in $A, 2009$ and $B$, between 2009 and May 2015. Registered sites that have not contributed data are excluded. 
A. 2009

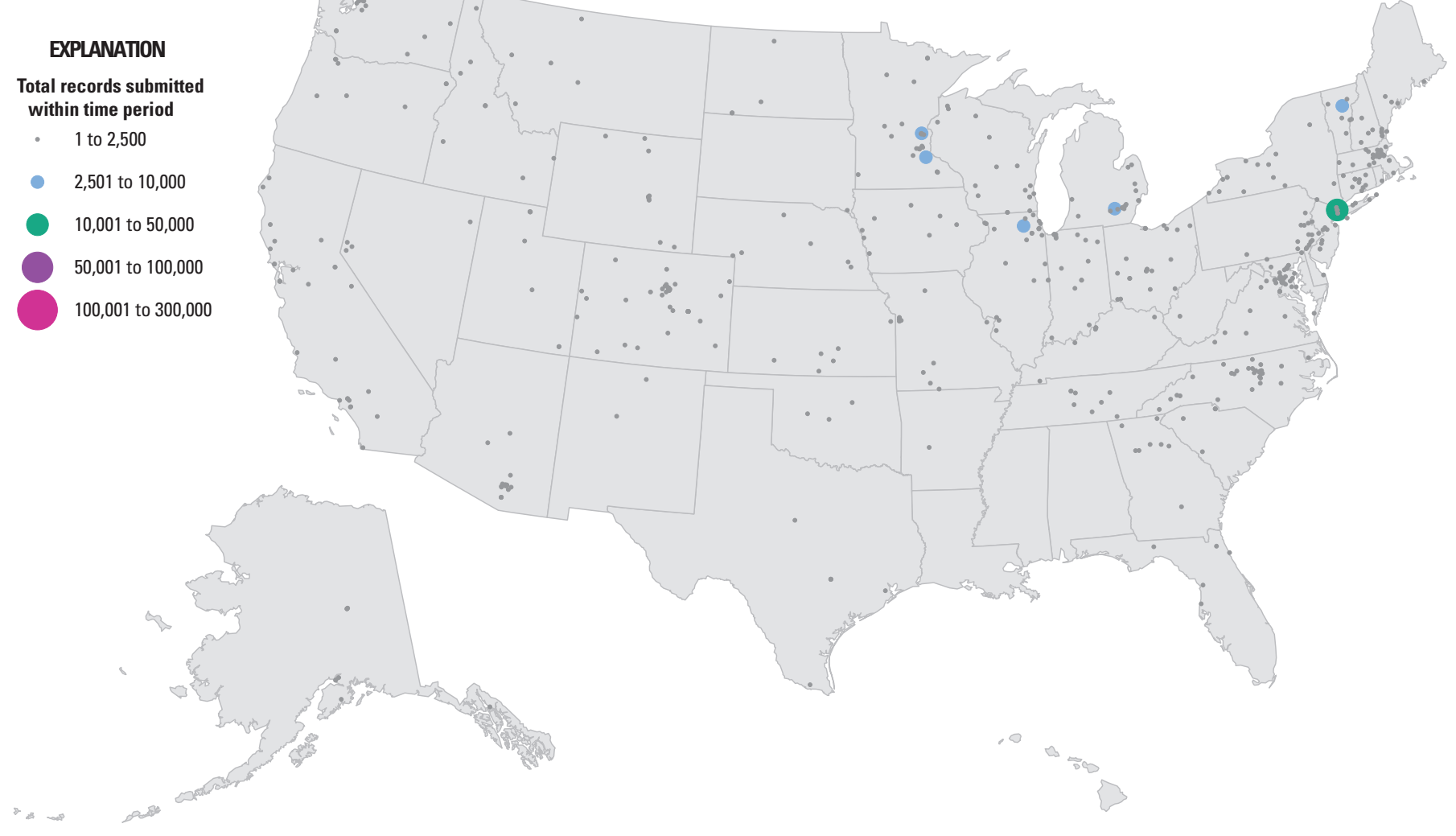

\section{B. 2009 to May 2015}




\section{Appendix 5. Advisory Committee Contributions and Perspective of USA-NPN Accomplishments Since 2007}

\author{
November 2014 report written by Geoffrey M. Henebry (South \\ Dakota State University), Chair of the USA-NPN Advisory \\ Committee
}

Although the NCO of the USA-NPN is largely supported by the USGS, it is important to recognize that the USA-NPN is an effort much broader than the NCO and that, to date, the planning effort alone has engaged several hundred people. The end result of all of these collaborations both in and out of the USGS-funded NCO has been rapid growth of a large "community of practice" for phenology.

The founding stages of the USA-NPN were accomplished at three planning workshops in August 2005, March 2006, and October 2006, funded by two small NSF grants to Mark Schwartz and Julio Betancourt with matching funds from seven Federal agencies (USGS, NPS, FWS, NASA, NOAA, EPA, and USDA-Forest Service).

The in-kind contributions of the members of what was initially the Implementation Team, then the Board of Directors (BOD), and is now the Advisory Committee (AC) have been considerable, including thousands of hours of time and expertise donated in support of the establishment, implementation, growth, and development of the $\mathrm{NCO}$ and the broader network. The contributions of the $\mathrm{BOD} / \mathrm{AC}$ members have ranged far and wide, including providing extensive technical guidance on cyberinfrastructure, integrating an existing lilac monitoring effort into the USA-NPN, and co-leading a new regional phenology network with the National Park Service.

A vital component of the USA-NPN build-out has been the NSF Research Coordination Network (RCN) grant of $\$ 500,000$, for which Professor Mark Schwartz served as the principal investigator (PI) from 2007 to 2014, with co-PI's Dr. Susan Mazer (a member of the AC) and Dr. Jake Weltzin, NCO Executive Director. The RCN sponsored several critical meetings for the USA-NPN during 2007 to 2013. Examples of scholarly and community building activities arising from these RCN meetings include

1. The RCN subsidized travel to the annual meeting for the Board of Directors (and later the Advisory Committee) and has subsidized a few small working group meetings (e.g., Species and Protocols, October 2008 in Tucson; Cyberinfrastructure, September 2010 in Milwaukee) and even an Agency Information and Listening Session attended by more than 40 administrators from 10 Federal agencies held in May 2011 at the National Geographic Society Headquarters in Washington, D.C.

2. Development of related regional and national monitoring efforts (e.g., Project Budburst and the California Phenology Project both grew out of annual RCN workshops).

3. Regular RCN meeting reports co-authored by BOD or $\mathrm{AC}$ and (or) NCO members in EOS (e.g., Betancourt and others, 2005; Betancourt and others, 2007; Henebry and Betancourt, 2010; Schwartz and others, 2013) and synthesis papers conceived and planned during the RCN meeting (see list below).

4. A successful National Center for Ecological Analysis and Synthesis (NCEAS) grant and working group entitled, "Forecasting phenology: Integrating ecology climatology, and phylogeny to understand plant responses to climate change," which held three workshops and generated a dozen high profile publications [listed at http://www. nceas.ucsb.edu/projects/12574; see reference list below] and two Northern Hemisphere databases on historical phenological observations for multiple species and sites: (1) phenological responses to warming experiments (Synthesis of Timings Observed in iNcrease Experiments [STONE]; https://knb.ecoinformatics.org/\#view/ doi:10.5063/F10V89RP); and (2) Network of Ecological and Climatological Timings Across Regions (NECTAR; https://knb.ecoinformatics.org/\#view/nceas.988.17).

5. Phenology special sessions at major scientific conferences, that is, AGU Fall Meeting (2007-14), European Geosciences Union (2012-14), US-IALE (2007-14), and ESA (2010, 2011, 2013), and tutorial workshops at US-IALE in 2008, 2010, 2012 on "Introduction to Land Surface Phenology."

6. The Phenology 2012 international meeting (http://www4. uwm.edu/letsci/conferences/phenology2012/).

7. Completion of second edition of "Phenology: An Integrative Environmental Science" published by Springer in 2013 (Schwartz, 2013).

8. Multiple grant proposals submitted to NASA, NSF, and USGS, of which several were supported.

\section{RCN Meeting Reports Published in Eos}

Betancourt, J.L., Schwartz, M.D., Breshears, D.D., Brewer, C.A., Frazer, G., Gross, J.E., Mazer, S.J., Reed, B.C., and Wilson, B.E., 2007, Evolving plans for a USA National Phenology Network: Eos Transactions American Geophysical Union, v. 88, p. 211.

Betancourt, J.L., Schwartz, M.D., Breshears, D.D., Cayan, D.R., Dettinger, M.D., Inouye, D.W., Post, E., and Reed, B.C., 2005, Implementing a U.S. national phenology network: Eos Transactions American Geophysical Union, v. 86, p. 539,542 . 
Henebry, G.M., and Betancourt, J.L., 2010, Toward a U.S. national phenological assessment: Eos Transactions American Geophysical Union, v. 91, no. 1, p. 3.

Schwartz, M.D., Enquist, C.A.F., and Denny, E.G., 2013, Phenological implications of warming temperatures and extreme climatic events: Eos Transactions American Geophysical Union, v. 94, no. 10, p. 99.

\section{Examples of Synthesis Articles that Originated at RCN Meetings}

Alemu, W.G., and Henebry, G.M., 2013, Land surface phenologies and seasonalities using cool earthlight in mid-latitude croplands: Environmental Research Letters, v. 8, no. 4, accessed April 17, 2015, at http://dx.doi.org/10.1088/17489326/8/4/045002.

Ault, T.R., Henebry, G.M., de Beurs, K.M., Schwartz, M.D., Betancourt, J.L., and Moore, D., 2013, The false spring of 2012, Earliest in North American record: Eos Transactions American Geophysical Union, v. 94, no. 20, p. 181-182.

Ault, T.R., Schwartz, M.D., Zurita-Milla, R., Weltzin, J.F., and Betancourt, J.L., in press, Trends and natural variability of spring onset in the coterminous United States as evaluated by a new gridded dataset of spring indices: Journal of Climate [accepted June 25, 2015].

Cleland, E.E., Chuine, I., Menzel, A., Mooney, H.A., and Schwartz, M.D., 2007, Shifting plant phenology in response to global change: Trends in Ecology and Evolution, v. 22, p. 357-365.

Cook, B.I., Terando, A., and Steiner, A., 2010, Ecological forecasting under climatic data uncertainties-A case study in phenological modeling: Environmental Research Letters, v. 5, no. 4, 7 p., accessed April 17, 2015, at http://dx.doi. org/10.1088/1748-9326/5/4/044014.

de Beurs, K.M., Cook, R., Mazer, S.J., Haggerty, B., Hove, A., Henebry, G.M., Beaubien, E., Barnett, L., Thomas, C.L., and Pohlad, B.R., 2013, Phenology in higher educationGround-based and spatial analysis tools, in Schwartz, M.D., ed., Phenology - An integrative environmental science $(2 \mathrm{~d}$ ed.): Springer, chap. 31, p. 585-602, accessed April 17, 2015, at http://dx.doi.org/10.1007/978-94-007-6925-0_31.

de Beurs, K.M., and Henebry, G.M., 2013, Vegetation phenology in global change, in Schwartz, M.D., ed., Phenology-An integrative environmental science ( $2 \mathrm{~d}$ ed.): Springer, chap. 26, p. 483-502, accessed April 17, 2015, at http://dx.doi.org/10.1007/978-94-007-6925-0_26.

Diez, J.M., Miller-Rushing, A.J., Mazer, S.J., Crimmins, T.M., Crimmins, M.A., Bertelsen, C.D., and Inouye, D.W., 2012, Forecasting phenology - From species variability to community forecasts: Ecology Letters, v. 15, p. 545-553.
Henebry, G.M., 2013, Phenologies of North American grasslands and grasses, in Schwartz, M.D., ed., PhenologyAn integrative environmental science ( $2 \mathrm{~d}$ ed.): Springer, chap. 11, p. 197-210, accessed April 17, 2015, at http:// dx.doi.org/10.1007/978-94-007-6925-0_11.

Henebry, G.M., and de Beurs, K.M., 2013, Remote sensing of land surface phenology-A prospectus, in Schwartz, M.D., ed., Phenology - An integrative environmental science (2d ed.): Springer, chap. 21, p. 385-411, accessed April 17, 2015, at http://dx.doi.org/10.1007/978-94-007-6925-0_21.

Kim, Y., Kimball, J.S., Didan, K., and Henebry, G.M., 2014, Response of vegetation growth and productivity to spring climate indicators in the conterminous United States derived from satellite remote sensing data fusion: Agricultural and Forest Meteorology, v. 194, p. 132-143, accessed April 17, 2015, at http://dx.doi.org/10.1016/j.agrformet.2014.04.001.

McCabe, G.J., Ault, T.R., Cook, B.I., Betancourt, J.L., and Schwartz, M.D., 2012, Influences of the El Niño Southern Oscillation and the Pacific Decadal Oscillation on the timing of North American spring: International Journal of Climatology, v. 32, no. 15, p. 2301-2310, accessed April 17, 2015, at http://dx.doi.org/10.1002/joc.3400.

McCabe, G.J., Betancourt, J.L., and Feng, S., 2015, Variability in the start, end, and length of frost-free periods across the conterminous United States during the past century: International Journal of Climatology, accessed April 27, 2015, at http://dx.doi.org/10.1002/joc.4315.

McCabe, G.J., Betancourt, J.L., Pederson, G.T., and Schwartz, M.D., 2013, Variability common to first leaf dates and snowpack in the western conterminous United States: Earth Interactions, v. 17, p. 1-18.

Morisette, J.T., Richardson, A.D., Knapp, A.K., Fisher, J.I., Graham, E.A., Abatzoglou, J., Wilson, B.E., Breshears, D.D., Henebry, G.M., Hanes, J.M., and Liang, L., 2009, Tracking the rhythm of the seasons in the face of global change-Phenological research in the 21st century: Frontiers in Ecology and the Environment, v. 7, no. 5, p. 253-260, accessed April 17, 2015, at http://dx.doi. org/10.1890/070217.

Post, E., and Inouye, D.W., 2008, Phenology—Response, driver, and integrator (Introduction to Special Feature): Ecology, v. 89, no. 2, p. 319-320.

Schwartz, M.D., ed., 2013, Phenology-An integrative environmental science ( $2 \mathrm{~d}$ ed.): Netherlands, Springer, $610 \mathrm{p}$.

Schwartz, M.D., Ault, T.R., and Betancourt, J.L., 2013, Spring onset variations and trends in the continental U.S.A.-Past and regional assessment using temperature-based indices: International Journal of Climatology, v. 33, no. 11, p. 2917-2922. 
Schwartz, M.D., Betancourt, J.L., and Weltzin, J.F., 2012, From Caprio's lilacs to the USA National Phenology Network: Frontiers in Ecology and the Environment, v. 10, no. 6, p. 324-327.

Strong, C., Zuckerberg, B., Betancourt, J.L., and Koenig, W., 2015, Climatic dipoles drive two principal modes of North American boreal bird irruption: Proceedings of the National Academy of Sciences, accessed May 15, 2015, at http:// www.pnas.org/cgi/doi/10.1073/pnas.1418414112.

\section{Examples of Publications from NCEAS Working Group on Forecasting Phenology}

Ault, T.R., Macalady, A.K., Pederson, G.T., Betancourt, J.L., and Schwartz, M.D., 2011, Northern Hemisphere modes of variability and the timing of spring in western North America: Journal of Climate, v. 24, p. 4003-4014.

Cleland, E.E., Allen, J.M., Crimmins, T.M., Dunne, J.A., Pau, S., Travers, S.E., Zavaleta, E., and Wolkovich, E.M, 2012, Phenological tracking enables positive species responses to climate change: Ecology, v. 93, p. 1765-1771.

Cook, B.I., Wolkovich, E.M., Davies, T.J., Ault, T.R., Betancourt, J.L., Allen, J.M., Bolmgren, K., Cleland, E.E., Crimmins, T.M., Kraft, N.J.B., Lancaster, L.T., Mazer, S.J., McCabe, G.J., McGill, B.J., Parmesan, C., Pau, S., Regetz, J., Salamin, N., Schwartz, M.D., and Travers, S.E., 2012, Sensitivity of spring phenology to warming across temporal and spatial climate gradients in two independent databases: Ecosystems, v. 15, p. 1283-1294, accessed April 17, 2015, at http://dx.doi.org/ 10.1007/s10021-012-9584-5.

Cook, B.I., Wolkovich, E.M., and Parmesan, C., 2012, Divergent responses to spring and winter warming drive community level flowering trends: Proceedings of the National Academy of Sciences, v. 109, p. 9000-9005, accessed April 17, 2015, at http://dx.doi.org/ 10.1073/ pnas. 1118364109.

Davies, T.J., Kraft, N.J.B., Salamin, N., and Wolkovich, E.M., 2012, Incompletely resolved phylogenetic trees inflate estimates of phylogenetic conservatism: Ecology, v. 93, p. 242-247.

Davies, T.J., Wolkovich, E.M., Kraft, N.J.B., Salamin, N., Allen, J.M., Ault, T.R., Betancourt, J.L., Bolmgren, K., Cleland, E.E., Cook, B.I., Crimmins, T.M., Mazer, S.J.,
McCabe, G.R., Pau, S., Regetz, J., Schwartz, M.D., and Travers, S.E., 2013, Phylogenetic conservatism in plant phenology: Journal of Ecology, v. 101, no. 6, p. 1520-1530, accessed April 17, 2015, at http://dx.doi.org/ 10.1111/13652745.12154 .

Mazer, S.J., Travers, S.E., Cook, B.I., Davies, T.J., Bolmgren, K., Kraft, N.J.B., Salamin, N., and Inouye, D.W., 2013, Flowering date of taxonomic families predicts phenological sensitivity to temperature-Implications for forecasting the effects of climate change on unstudied taxa: American Journal of Botany, v. 100, no. 7, p. 1381-1397, accessed April 17, 2015, at http://dx.doi.org/10.3732/ajb.1200455.

McCabe, G.J., Ault, T.R., Cook, B.I., Betancourt, J.L., and Schwartz, M.D., 2012, Influences of the El Niño Southern Oscillation and the Pacific Decadal Oscillation on the timing of the North American spring: International Journal of Climatology, v. 32, no. 15, p. 2301-2310.

Pau, S., Wolkovich, E.M., Cook, B.I., Davies, T.J., Kraft, N.J.B., Bolmgren, K., Betancourt, J.L., and Cleland, E.E., 2011, Predicting phenology by integrating ecology, evolution and climate science: Global Change Biology, v. 17, p. 3633-3643.

Pau, S., Wolkovich, E.M., Cook, B.I., Nytch, C.J., Regetz, J., Zimmerman, J.K., and Wright, S.J., 2013, Clouds and temperature drive dynamic changes in tropical flower production: Nature Climate Change, v. 3, p. 838-842, accessed April 17, 2015, at http://dx.doi.org/ 10.1038/nclimate1934.

Wolkovich, E.M., Cook, B.I., Allen, J.M., Crimmins, T.M., Betancourt, J.L., Travers, S.E., Pau, S., Regetz, J., Davies, T.J., Kraft, N.J.B., Ault, T.R., Bolmgren, K., Mazer, S.J., McCabe, G.J., McGill, B.J., Parmesan, C., Salamin, N., Schwartz, M.D., and Cleland, E.E., 2012, Warming experiments underpredict plant phenological responses to climate change: Nature, v. 485, p. 494-497, accessed April 17, 2015, at http://dx.doi.org/10.1038/nature11014.

Wolkovich, E.M., Davies, T.J., Schaefer, H., Cleland, E.E., Cook, B.I., Travers, S.E., Willis, C.G., and Davis, C.C., 2012, Temperature-dependent shifts in phenology contribute to the success of exotic species with climate change: American Journal of Botany, v. 100, p. 1407-1421, accessed April 17, 2015, at http://dx.doi.org/ 10.3732/ajb.1200478. 


\section{Appendix 6. Introduction to Federal Advisory Committees}

Written by Pierre D. Glynn with help from Wendy E. Norton (USGS), Executive Secretary, Advisory Committee on Water Information (ACWI)

As mentioned in the main text of this report, the possibility of creating a formal Federal Advisory Committee (FAC) that would include non-Federal members (and follow rules established by the Federal Advisory Committee Act) was considered but rejected by the review panel because of (1) the high creation and compliance costs of a FAC relative to the current budget of the USA-NPN and (2) the current need to increase USGS and Federal ownership (and support) of the USA-NPN.

The USGS has several FACs currently in operation as of October 2014, including (1) the Advisory Committee on Climate Change and Natural Resource Science (ACCCNRS; https://nccwsc.usgs.gov/accenrs) and (2) the Advisory Committee on Water Information (ACWI; http://acwi.gov/). ACCCNRS is a 25 -member committee that advises the USGS National Climate Change and Wildlife Science Center and includes representatives from Federal agencies; Tribal, State, and local governments; nongovernment organizations; academic institutions; and the private sector. ACWI advises the Department of the Interior (DOI) and has representatives from up to 35 different public and private entities, including professional associations and academia.

The cost of establishing and running a FAC depends on the size, processes, and goals of the FAC. For example, the USGS office running the ACWI FAC has an annual budget of about $\$ 750,000$, with the majority of that amount $(\$ 500,000$ $\$ 600,000$ ) being staff salaries (although some of the staff also have other duties that are unrelated to ACWI). ACWI is a large
FAC that has nine active subcommittees, each with three or more workgroups. Most of the remaining funds, beyond salary, pay for invitational travel to ensure that ACWI's non-Federal members can attend meetings. Depending on travel restrictions, timing of major conferences, and other factors, invitational travel costs for the ACWI FAC are between $\$ 60,000$ and $\$ 150,000+$ each year. ACWI and its subcommittees collectively have more than 100 members and hold dozens of meetings and teleconferences every year. Another cost is the small fee (about \$300) for posting notices in the Federal Register: the notices are required every time there is a meeting of the full FAC, ${ }^{*}$ every time there is a membership vacancy, and every time the FAC charter is renewed. Other tasks involved in FAC operations include (1) maintaining the FAC Web site(s); (2) maintaining membership lists for the FAC and its groups and subgoups; (3) logistics work for conference calls, meetings, and travel; (4) recording of call and meeting minutes; (5) annual FAC data entry into the FAC database of the General Services Administration (http://facadatabase.gov); (6) maintenance of all FAC official files, materials, and records; ${ }^{* *}$ and (7) preparation, tracking, and responses for the DOI conference approval process (currently required for face-to-face meetings involving 30 or more people, with 15 or more people in travel status).

"Notices are not required for meetings of subcommittees and workgroups.

${ }^{* *}$ Record requirements for FACs differ from other Federal record requirements in that FAC files must be maintained onsite for the full lifetime of the FAC. 



\title{
Back cover photographs.
}

Left, A rancher in central Texas examines a juniper to understand patterns of pollen production for human health applications. Photograph by Mechelle Meixner.

Right, Students learn to observe plant and animal phenology at Jean Lafitte National Historical Park and Preserve, Louisiana. Photograph by Carolyn A.F. Enquist, U.S. Geological Survey.

\author{
For more information concerning this publication, contact: \\ Jake F. Weltzin, Executive Director \\ USA National Phenology Network \\ National Coordinating Office \\ 1955 E. Sixth Street \\ Tucson, AZ 85721 \\ jweltzin@usgs.gov \\ http://www.usanpn.org \\ Publishing support provided by the USGS Science Publishing Network \\ Publishing Service Centers (PSC) \\ Editing by Kay Naugle, Raleigh PSC \\ Illustrations and layout by Jeannette M. Foltz, Reston PSC \\ Web support by Angela E. Hall, Reston PSC
}



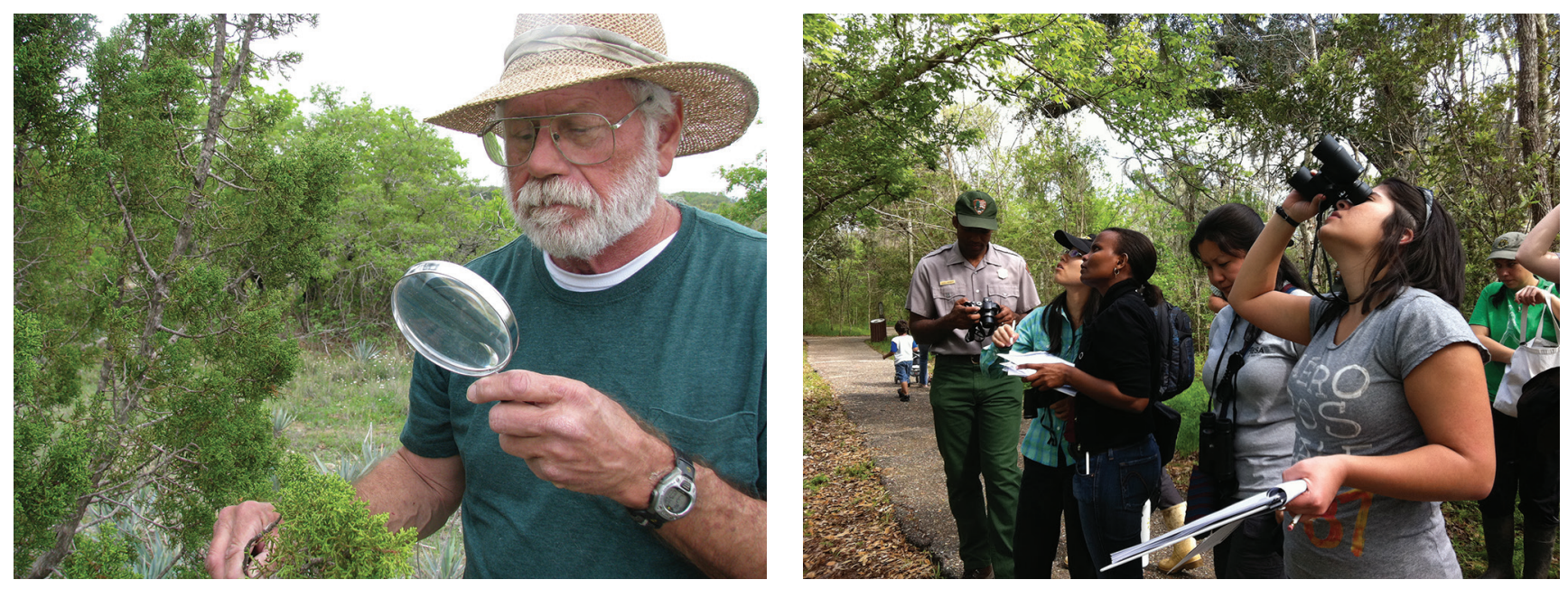

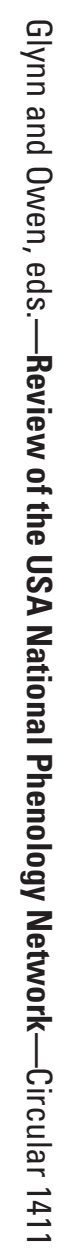

